\title{
Facile entry to substituted decahydroquinoline alkaloids. Total synthesis of lepadins A-E and $H$
}

\author{
Xiaotao $\mathrm{Pu}$ and Dawei Ma* \\ State Key Laboratory of Bioorganic and Natural Products Chemistry, Shanghai \\ Institute of Organic Chemistry, Chinese Academy of Sciences, 354 Fenglin Lu, \\ Shanghai 200032, China \\ madw@mail.sioc.ac.cn
}

Supporting Information

Table of Contents

Experimental for preparing compounds $\mathbf{8}, \mathbf{1 6}, \mathbf{2 7}, \mathbf{2 8}, \mathbf{3 3}$, and 35---------------------S2

Copies of ${ }^{1} \mathrm{H}$ NMR and ${ }^{13} \mathrm{C}$ NMR spectrum of compounds 11, 14, 7, 18, 22, 23, 1a, 1b,

$27,28,1 c, 35,36,43-45,2 a-c----$ 


\section{Experimental}

\section{(2S,3R)-3-(tert-Butyloxycarbonyl)amino-2-(tert-butyldimethylsilyloxy)-}

butyl bromide 8. To a solution of $9(8.2 \mathrm{~g}, 30.6 \mathrm{mmol})$ in dry DMF $(15 \mathrm{~mL})$ were added TBSCl (5.6 g, $37 \mathrm{mmol})$ and imidazole $(6.4 \mathrm{~g}, 94 \mathrm{mmol})$. The mixture was stirred at room temperature for about $20 \mathrm{~h}$ before it was diluted with $\mathrm{CH}_{2} \mathrm{Cl}_{2}$. The organic layer was separated, washed with brine, dried over $\mathrm{MgSO}_{4}$ and concentrated. The residue was purified by chromatography eluting with 1:90 ethyl acetate/petroleum ether to give $9.3 \mathrm{~g}(80 \%)$ of $\mathbf{8}$ as a colorless oil. $[\alpha]_{\mathrm{D}}{ }^{19}-6.5\left(c 1.8, \mathrm{CHCl}_{3}\right) ;{ }^{1} \mathrm{H} \mathrm{NMR}$ $\left(300 \mathrm{MHz}, \mathrm{CDCl}_{3}\right) \delta 0.08(\mathrm{~s}, 3 \mathrm{H}), 0.11(\mathrm{~s}, 3 \mathrm{H}), 0.91(\mathrm{~s}, 9 \mathrm{H}), 1.05(\mathrm{~d}, J=6.9 \mathrm{~Hz}, 3 \mathrm{H})$, $1.41(\mathrm{~s}, 9 \mathrm{H}) 3.2-3.4(\mathrm{~m}, J=6.3,7.5,4.2 \mathrm{~Hz}, 2 \mathrm{H}), 3.90(\mathrm{brt}, J=6.0 \mathrm{~Hz}, 2 \mathrm{H}), 4.91(\mathrm{br} \mathrm{d}$, $J=6.6 \mathrm{~Hz}, 1 \mathrm{H}) ;{ }^{13} \mathrm{C} \mathrm{NMR}\left(75 \mathrm{MHz}, \mathrm{CDCl}_{3}\right) \delta-4.96,-4.32,12.9,18,25.8,28.4,32.8$, 48.2, 73.6, 79.3, 154.8; IR (neat) 3457, 3354, 1708, 1500, $1172 \mathrm{~cm}^{-1}$; ESI-MS m/z 404 $(\mathrm{M}+\mathrm{Na})^{+}$; ESI-HRMS calcd for $\mathrm{C}_{15} \mathrm{H}_{32} \mathrm{NO}_{3} \mathrm{BrSiNa}(\mathrm{M}+\mathrm{Na})^{+}$requires 404.1225, found 404.1227.

Wittig olefination of 7. To an ice cooled suspension of $\mathrm{Ph}_{3} \mathrm{P}^{+} \mathrm{CH}_{2} \mathrm{OMeCl}^{-}$ $(1.3 \mathrm{~g}, 3.8 \mathrm{mmol})$ in $6 \mathrm{~mL}$ of THF was added NaHMDS ( $2 \mathrm{M}$ in THF, $2 \mathrm{~mL})$. The resultant mixture was maintained at this temperature for $0.5 \mathrm{~h}$ with vigorous stirring. After the reaction mixture was put into a dry ice bath, a solution of ketone 7 (300 mg, $0.76 \mathrm{mmol}$ ) in $4 \mathrm{~mL}$ of THF was added dropwise via syringe. After addition, the reaction mixture was maintained at $-78{ }^{\circ} \mathrm{C}$ for $1 \mathrm{~h}$ and then allowed to warm to room temperature overnight. The resultant solution was diluted with ether before saturated aqueous ammonium chloride was added. The organic layer was separated and the 
aqueous layer was extracted with ethyl ether. The combined organic layers were dried over $\mathrm{MgSO}_{4}$ and concentrated in vacuo. The residue was purified by chromatography eluting with 1:60 ethyl acetate/petroleum ether to give $242 \mathrm{mg}$ (75\%) of enol ether 16 as a mixture of E- and Z-isomers, which was used without further purification.

Olefination of the aldehyde 18 with phosphonate 26 . To a stirred solution of phosphonate 26 (276 mg, $0.94 \mathrm{mmol}$ ) in $3 \mathrm{~mL}$ of DME was added KHMDS (1M in THF, $1.0 \mathrm{~mL}$ ) dropwise by a syringe at $-78{ }^{\circ} \mathrm{C}$ over $20 \mathrm{~min}$. The resultant solution was stirred for $0.5 \mathrm{~h}$ before a solution of the aldehyde $18(70 \mathrm{mg}, 0.24 \mathrm{mmol})$ in $2 \mathrm{~mL}$ of DME was added dropwise via syringe over $10 \mathrm{~min}$. The reaction mixture was maintained at $-78{ }^{\circ} \mathrm{C}$ for $6 \mathrm{~h}$ and then allowed to slowly warm to room temperature. The resultant solution was partitioned between ether and saturated ammonium chloride. The organic layer was separated and the aqueous layer was extracted with ether. The combined organic layers were dried over $\mathrm{MgSO}_{4}$ and concentrated in vacuo. The residue was purified by chromatography eluting with 1:10 ethyl acetate/petroleum ether to give $98 \mathrm{mg}(92 \%)$ of diene 27. $[\alpha]_{\mathrm{D}}{ }^{30}-1.9\left(c 0.6, \mathrm{CHCl}_{3}\right) ;{ }^{1} \mathrm{H} \mathrm{NMR}(300 \mathrm{MHz}$, $\left.\mathrm{CDCl}_{3}\right) \delta-0.01(\mathrm{~s}, 3 \mathrm{H}), 0.04(\mathrm{~s}, 3 \mathrm{H}), 0.87(\mathrm{~s}, 9 \mathrm{H}), 1.14(\mathrm{~d}, J=5.7 \mathrm{~Hz}, 3 \mathrm{H}), 1.25(\mathrm{q}$ like, $J=7.2,11.4 \mathrm{~Hz}, 1 \mathrm{H}), 1.33(\mathrm{~s}, 3 \mathrm{H}), 1.43-1.75(\mathrm{~m}, 10 \mathrm{H}), 1.97(\mathrm{dt}, J=1.8,2.1,9.0 \mathrm{~Hz}$ 1H), 2.17 (dd like, $J=7.5,7.2 \mathrm{~Hz}, 2 \mathrm{H}), 2.40(\mathrm{q}, J=12 \mathrm{~Hz}, 1 \mathrm{H}), 2.53(\mathrm{dq}, J=2.7,6.0 \mathrm{~Hz}$, 1H), $3.0($ br d, $J=1.1 \mathrm{~Hz}, 1 \mathrm{H}), 3.27$ (ddd, $J=2.4,6.0,6.7 \mathrm{~Hz}, 1 \mathrm{H}), 3.96$ (dd like, $J=4.2$, $3.3 \mathrm{~Hz}, 4 \mathrm{H}), 5.31(\mathrm{dd}, J=8.2,14.1 \mathrm{~Hz}, 1 \mathrm{H}), 5.57(\mathrm{dt}, J=7.2,14.2 \mathrm{~Hz}, 1 \mathrm{H}), 5.98(\mathrm{dd}, J$ $=7.2,14.4 \mathrm{~Hz}, 1 \mathrm{H}), 6.06(\mathrm{dd}, J=6.9,14.6 \mathrm{~Hz}, 1 \mathrm{H}) ;{ }^{13} \mathrm{C} \mathrm{NMR}\left(75 \mathrm{MHz}, \mathrm{CDCl}_{3}\right) \delta-4.7$, $-4.11,17.9,19.5,20.4,23.9,25.8,27.2,32.2,33.8,37.4,38.8,39.4,41.9,54.8,59.8$ 
64.6, 70.9, 109.8, 130.2, 130.5, 131.9, 136.6; IR (neat) 2930, 1473, $1376 \mathrm{~cm}^{-1}$; ESI-MS $m / z 450(\mathrm{M}+\mathrm{H})^{+} ;$HRMS calcd for $\mathrm{C}_{26} \mathrm{H}_{47} \mathrm{NO}_{3} \mathrm{Si}(\mathrm{M}+\mathrm{H})^{+}$requires 450.3398 , found 450.3397 .

$(2 S, 3 R, 4 \mathrm{a} S, 5 R, 8 \mathrm{a} R)-1-(t e r t-B u t y l o x y c a r b o n y l)-2-m e t h y l-3-h y d r o x y-5-((1 ' E$ ,3'E)-7-ethylenedioxy-octadien-1-yl)decahydroquinoline 28. To a solution of the diene 27 (80 mg, $0.178 \mathrm{mmol})$ in anhydrous benzene were sequentially added (Boc) $)_{2} \mathrm{O}$ (201 mg, $0.92 \mathrm{mmol})$ and $\mathrm{K}_{2} \mathrm{CO}_{3}(2 \mathrm{mg}, 0.015 \mathrm{mmol})$. The resultant mixture was heated to gently reflux under argon for $72 \mathrm{~h}$. After water was added to quench the reaction, the organic layer was separated and the aqueous layer was extracted with $\mathrm{CH}_{2} \mathrm{Cl}_{2}$. The combined organic layers were dried over $\mathrm{MgSO}_{4}$ and evaporated in vacuo. The residue was purified via chromatography eluting with 1:50 ethyl acetate/petroleum ether to give a crude carbamate. This product was dissolved in anhydrous $2 \mathrm{~mL}$ of THF before TBAF ( $2 \mathrm{M}$ in THF, $0.55 \mathrm{~mL}$ ) was added via syringe at room temperature. The reaction mixture was stirred for $36 \mathrm{~h}$, and then partitioned between ether and saturated ammonium chloride. The organic layer was separated and the aqueous layer was extracted with ether, and dried over $\mathrm{MgSO}_{4}$. After the solution was concentrated in vacuo, the residue was purified by chromatography eluting with 1:5 ethyl acetate/petroleum ether to give $65 \mathrm{mg}\left(85 \%\right.$ for two steps) of $\mathbf{2 8} .[\alpha]_{\mathrm{D}}{ }^{20}+9.8(c 0.5$, $\left.\mathrm{CHCl}_{3}\right) ;{ }^{1} \mathrm{H} \mathrm{NMR}\left(300 \mathrm{MHz}, \mathrm{CDCl}_{3}\right.$, amide rotamer) $\delta 1.17(\mathrm{~d}, J=7.8 \mathrm{~Hz}, 3 \mathrm{H}), 1.33(\mathrm{~s}$, $3 \mathrm{H}), 1.46(\mathrm{~s}, 9 \mathrm{H}), 1.45-1.55(\mathrm{~m}, 5 \mathrm{H}), 1.67-1.75(\mathrm{~m}, 5 \mathrm{H}), 2.07(\mathrm{dt}, J=1.5,12.0 \mathrm{~Hz}, 1 \mathrm{H})$, $2.13(\mathrm{~m}, 1 \mathrm{H}), 2.17(\mathrm{~m}, 2 \mathrm{H}), 2.21(\mathrm{~m}, 1 \mathrm{H}), 3.83(\mathrm{br} \mathrm{d}, J=1.1 \mathrm{~Hz}, 1 \mathrm{H}) 3.94(\mathrm{q}$ like, $J=2.9$ $4.0 \mathrm{~Hz}, 4 \mathrm{H}), 4.12(\mathrm{dq}, J=2.9,6.4 \mathrm{~Hz}, 1 \mathrm{H}), 4.15(\mathrm{br} \mathrm{s}, 1 \mathrm{H}), 5.60(\mathrm{dt}, J=6.9,14.2 \mathrm{~Hz}$, 
1H), $5.82(\mathrm{dd}, J=7.2,14.4 \mathrm{~Hz}, 1 \mathrm{H}), 6.01(\mathrm{dd}, J=6.5,14.5 \mathrm{~Hz}, 1 \mathrm{H}), 6.05(\mathrm{dd}, J=5.9$, $14.5 \mathrm{~Hz}, 1 \mathrm{H}) ;{ }^{13} \mathrm{C} \mathrm{NMR}\left(75 \mathrm{MHz}, \mathrm{CDCl}_{3}\right.$, amide rotamer) $\delta 20.1,21.1,23.9,25.8,27.2$, 27.87, 28.1, 28.5, 29.6, 32.6, 38.7, 42.1, 49.9, 53.4, 64.6, 69.5, 79.5, 109.8, 130.1, 130.5, 132.4, 135.0, 155.7; IR (neat) 3426, $1681 \mathrm{~cm}^{-1}$; ESI-MS m/z $436(\mathrm{M}+\mathrm{H})^{+}$; HRMS calcd for $\mathrm{C}_{25} \mathrm{H}_{42} \mathrm{NO}_{5}(\mathrm{M}+\mathrm{H})^{+}$requires 436.3063, found 436.3079 .

Peterson reaction of the ketone 7 with $\mathrm{TMSCH}_{2} \mathrm{CO}_{2}$ Et. To a solution of $\mathrm{TMSCH}_{2} \mathrm{COOEt}(324.8 \mathrm{mg}, 2.03 \mathrm{mmol})$ in $2 \mathrm{~mL}$ THF was added LDA ( $2 \mathrm{M}$ in THF, $1.04 \mathrm{~mL}$ ) at $-78^{\circ} \mathrm{C}$. After the mixture was maintained at this temperature for $0.5 \mathrm{~h}$ with vigorous stirring, a solution of 7 (403 $\mathrm{mg}, 1.02 \mathrm{mmol})$ in $2 \mathrm{~mL}$ THF was added dropwise via syringe. After addition, the reaction mixture was stirred at $-78^{\circ} \mathrm{C}$ for $1 \mathrm{~h}$ and then allowed to warm to room temperature overnight. The resultant solution was partitioned between ether and saturated ammonium chloride. The organic layer was separated and the aqueous layer was extracted with ether. The combined organic layers were dried over $\mathrm{MgSO}_{4}$ and concentrated in vacuo. The residue was purified by chromatography eluting with 1:30 ethyl acetate/petroleum ether to give $461 \mathrm{mg}$ (98\%, $\mathrm{E} / \mathrm{Z}=15: 1)$ of olefin 33. $[\alpha]_{\mathrm{D}}{ }^{20}-7.5\left(c 0.15, \mathrm{CHCl}_{3}\right) ;{ }^{1} \mathrm{H} \mathrm{NMR}\left(300 \mathrm{MHz}, \mathrm{CDCl}_{3}\right.$, major isomer) $\delta 0.05(\mathrm{~s}, 3 \mathrm{H}), 0.08(\mathrm{~s}, 3 \mathrm{H}), 0.86(\mathrm{~s}, 9 \mathrm{H}), 1.15(\mathrm{~d}, J=6.9 \mathrm{~Hz}, 3 \mathrm{H})$, $1.21-1.35(\mathrm{t}$ and $\mathrm{m}, J=7.2 \mathrm{~Hz}, 6 \mathrm{H}), 1.44(\mathrm{~s}, 9 \mathrm{H}), 1.61-1.80(\mathrm{~m}, 4 \mathrm{H}), 2.12(\mathrm{ddd}, J=1.8$ 12.6, $12.8 \mathrm{~Hz}, 1 \mathrm{H}), 2.91(\mathrm{brd}, J=5.1 \mathrm{~Hz}, 1 \mathrm{H}), 3.75$ and $3.78(\mathrm{~s}, 1 \mathrm{H}$ in $1: 2$ ratio due to rotamer), 4.03-4.18 (q and $\mathrm{m}, 3 \mathrm{H}), 5.67$ and 5.72 (s, $1 \mathrm{H}$ in 1:2 ratio due to rotamer); IR (neat) 1729, $1647 \mathrm{~cm}^{-1}$; ESI-MS $\mathrm{m} / \mathrm{z} 468(\mathrm{M}+\mathrm{H})^{+}$; HRMS (ESI) calcd for $\mathrm{C}_{25} \mathrm{H}_{45} \mathrm{NO}_{5} \mathrm{SiNa}(\mathrm{M}+\mathrm{Na})^{+}$requires 490.2951, found 490.2959. 
Olefin 35. To a solution of $\mathbf{3 3}(446 \mathrm{mg}, 1.02 \mathrm{mmol})$ in $20 \mathrm{~mL}$ of dry $\mathrm{CH}_{2} \mathrm{Cl}_{2}$ was added trifluoroacetic acid $(0.8 \mathrm{~mL})$ dropwise at room temperature. The reaction was carefully monitored by TLC, and quenched with methanolic $\mathrm{K}_{2} \mathrm{CO}_{3}$. After removal of solvent, the residue was chromatographed eluting with 1:1:0.01 petroleum ether/ethyl acetate/methanol to afford $370 \mathrm{mg}(100 \%)$ of $\mathbf{3 5} \cdot[\alpha]_{\mathrm{D}}{ }^{18}+21.5(c 0.37$, $\left.\mathrm{CHCl}_{3}\right) ;{ }^{1} \mathrm{H}$ NMR $\left(300 \mathrm{MHz}, \mathrm{CDCl}_{3}\right) \delta 0.09(\mathrm{~s}, 3 \mathrm{H}), 0.13(\mathrm{~s}, 3 \mathrm{H}), 0.89(\mathrm{~s}, 9 \mathrm{H}), 1.12$ (d, $J=6.2 \mathrm{~Hz}, 3 \mathrm{H}), 1.28(\mathrm{t}, J=7.2 \mathrm{~Hz}, 3 \mathrm{H}), 1.48-1.80(\mathrm{~m}, 7 \mathrm{H}), 2.21(\mathrm{dq}, J=2.0,14.0 \mathrm{~Hz}$ 1H), $2.56(\mathrm{~m}, 2 \mathrm{H}), 3.21$ (q like, $J=3.3 \mathrm{~Hz} 1 \mathrm{H}), 3.44(\mathrm{ddd}, J=4.3,5.4,11.0 \mathrm{~Hz}, 1 \mathrm{H})$, $3.96($ dd like, $J=1.5,13.2 \mathrm{~Hz}, 1 \mathrm{H}), 4.14(\mathrm{q}, J=7.2 \mathrm{~Hz}, 2 \mathrm{H}), 5.74(\mathrm{~s}, 1 \mathrm{H}) ;{ }^{13} \mathrm{C}$ NMR $(75$ $\left.\mathrm{MHz}, \mathrm{CDCl}_{3}\right) \delta-4.5,-4.0,14.3,18.0,19.3,21.8,25.9,29.5,31.7,36.0,43.9,57.7,59.6$ 59.9, 70.1, 115.1, 161.1, 166.6; IR (neat) 1719, $1643 \mathrm{~cm}^{-1}$; EI-MS m/z $367\left(\mathrm{M}^{+}\right), 352$, 322, 310, 220, 209, 166, 138; HRMS calcd for $\mathrm{C}_{20} \mathrm{H}_{37} \mathrm{NO}_{3} \mathrm{Si}\left(\mathrm{M}^{+}\right)$requires 367.2562, found 367.2581 . 


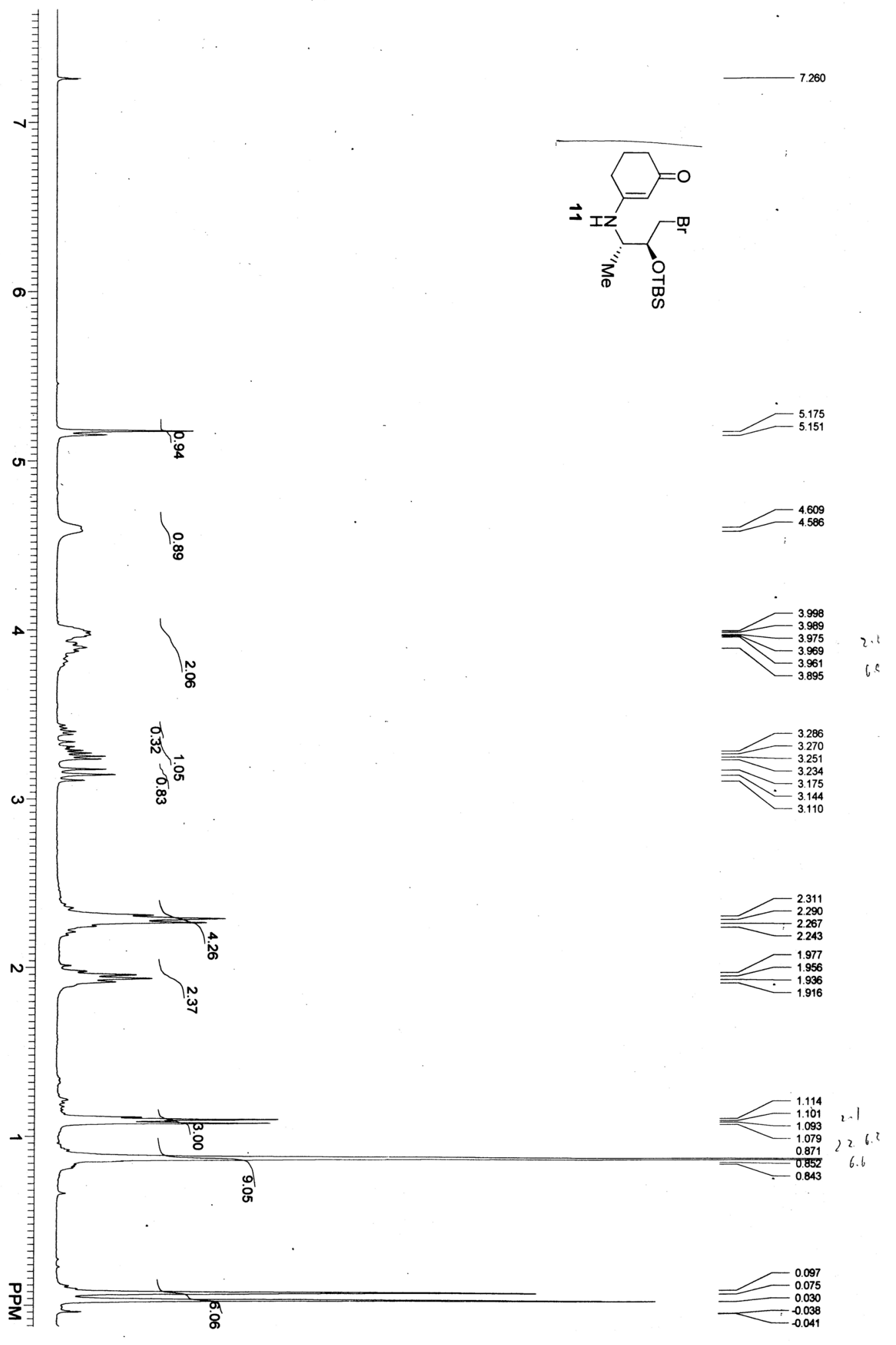




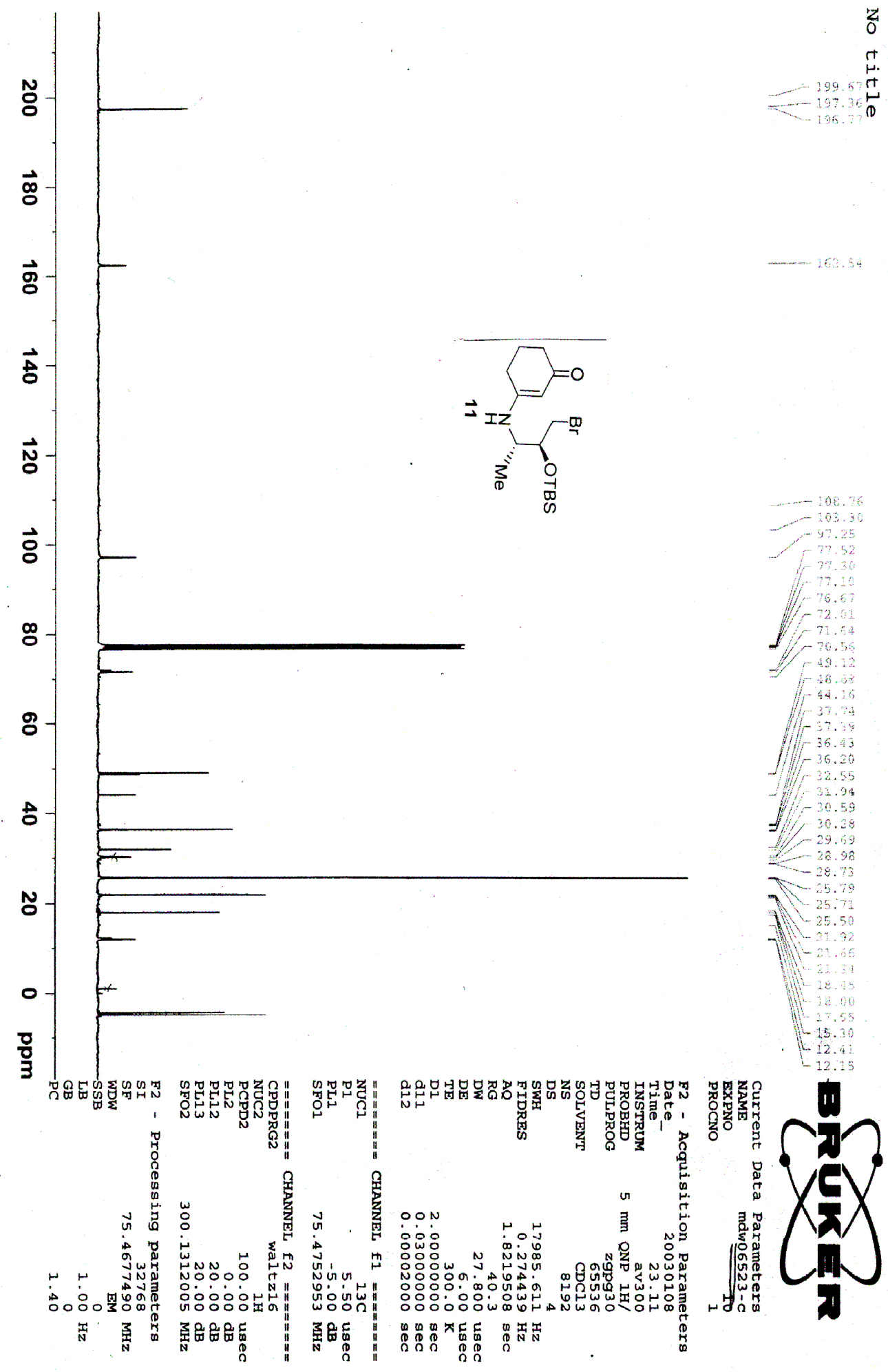




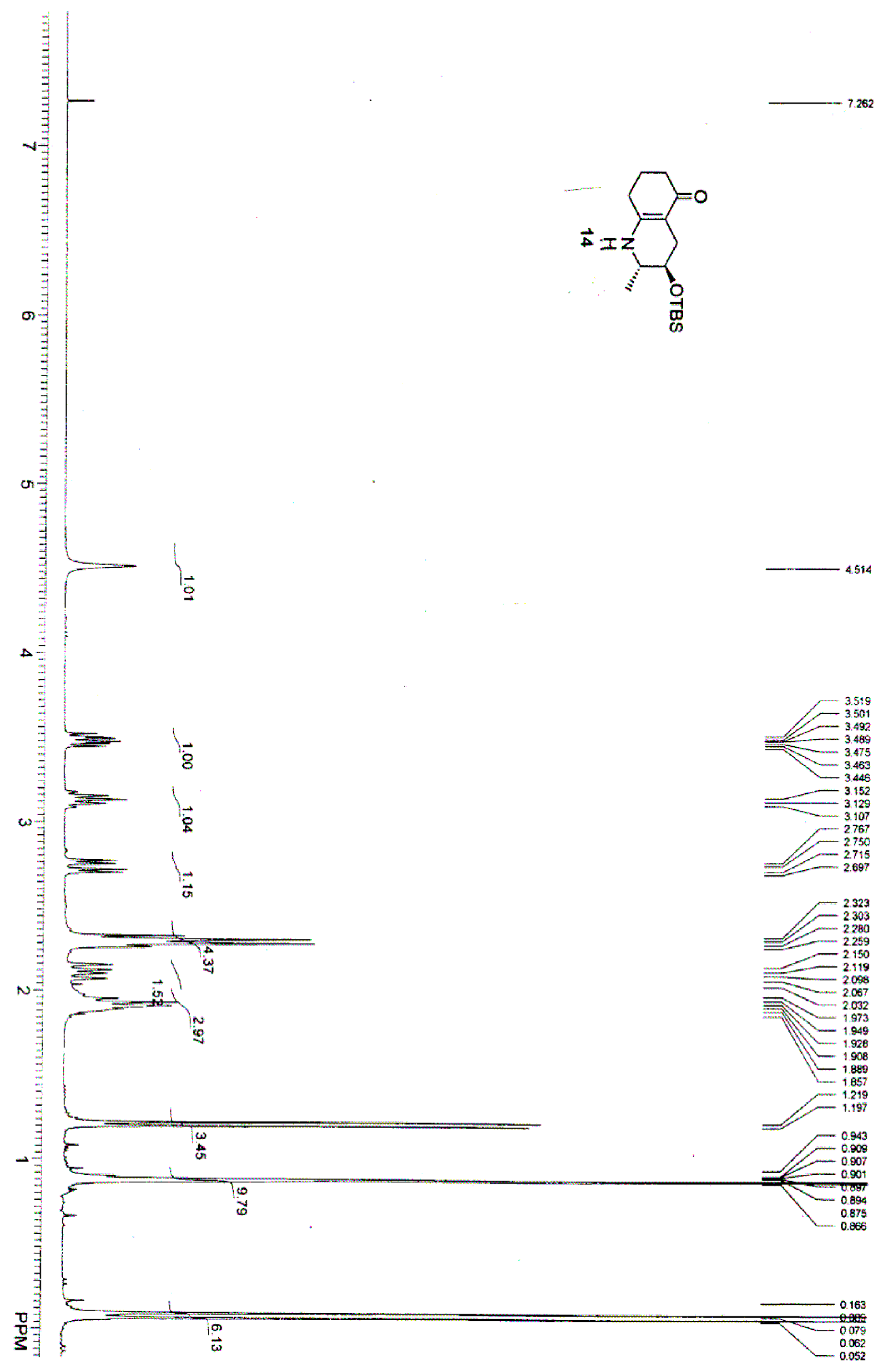




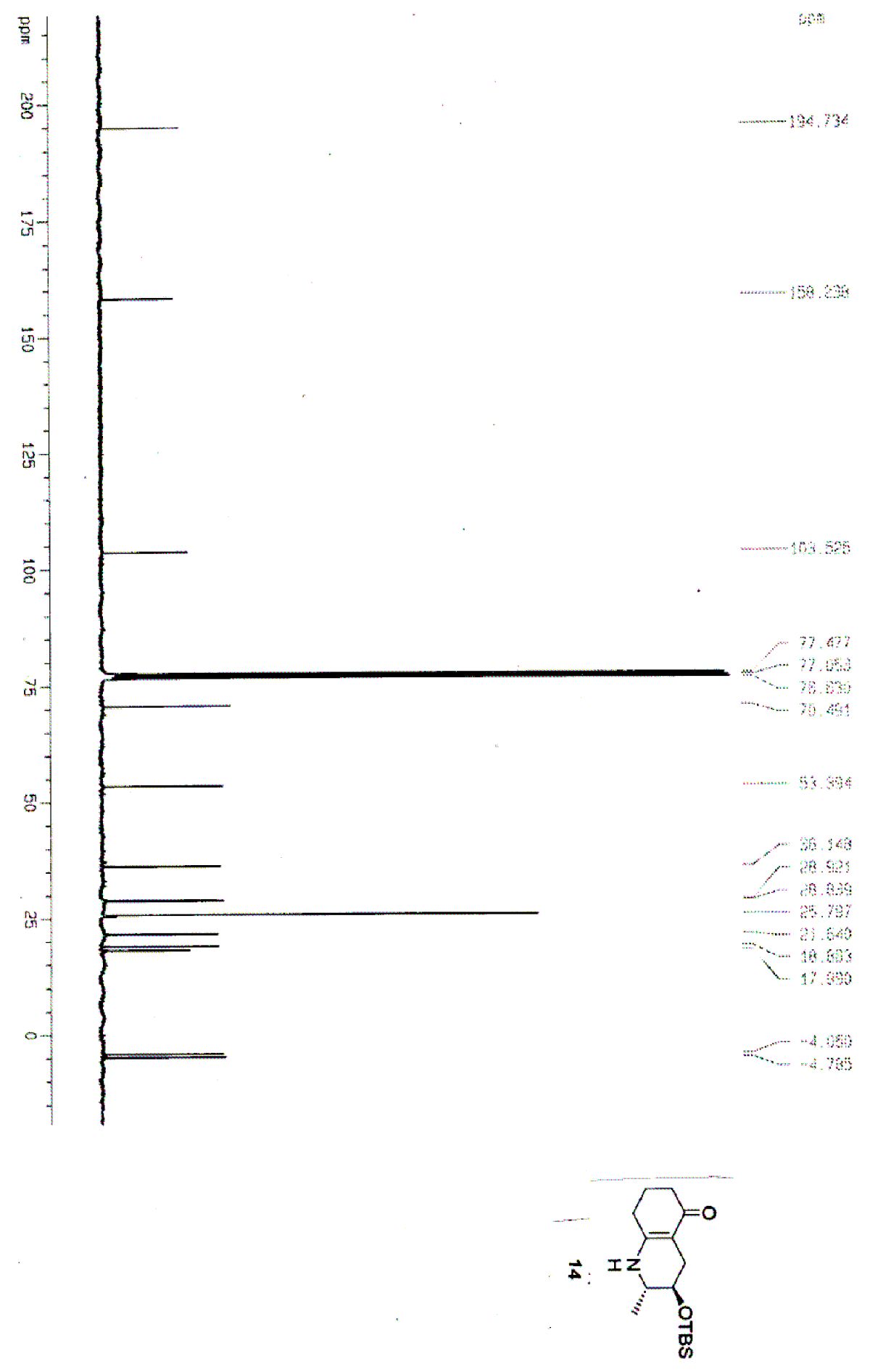




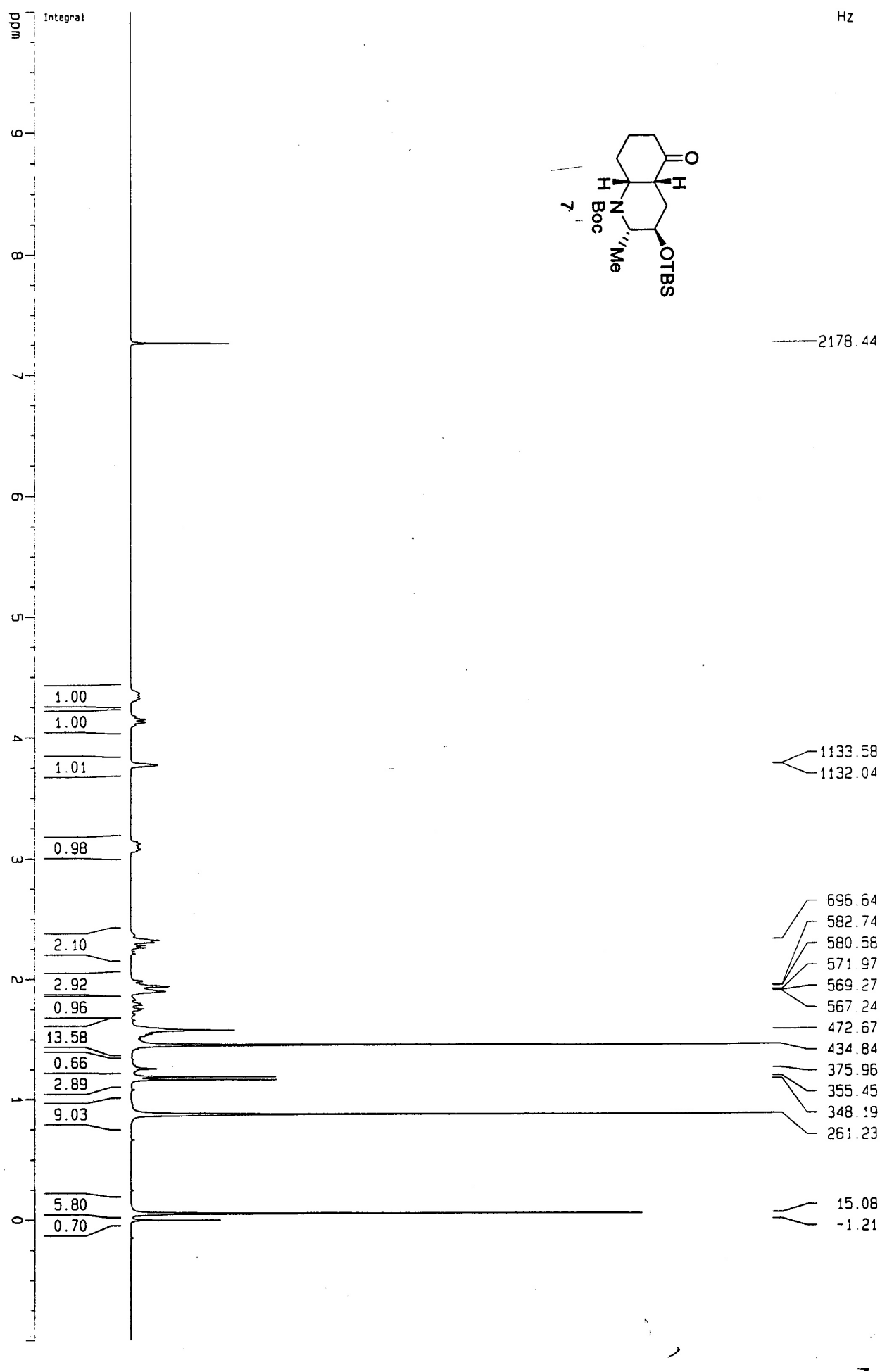



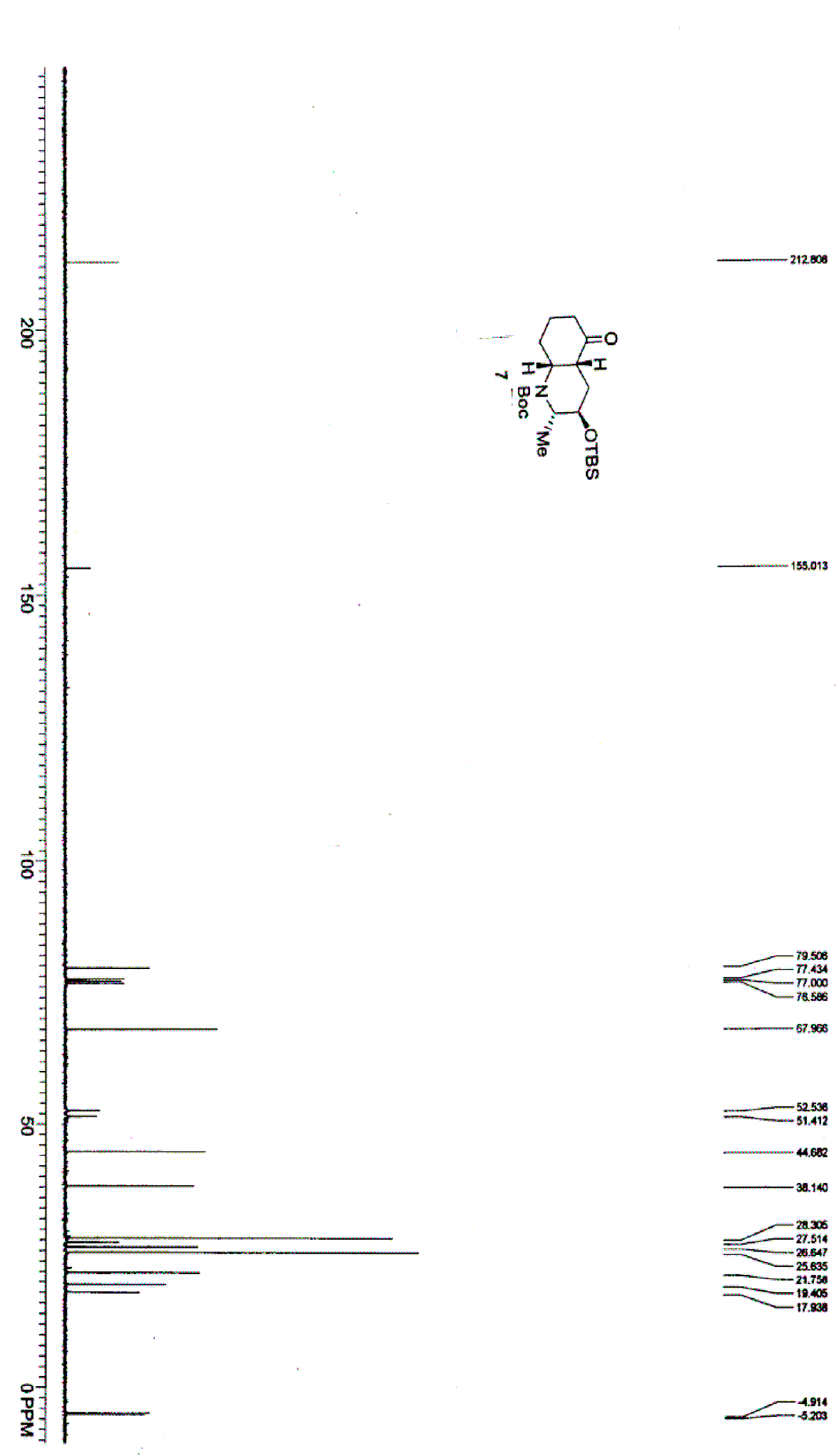


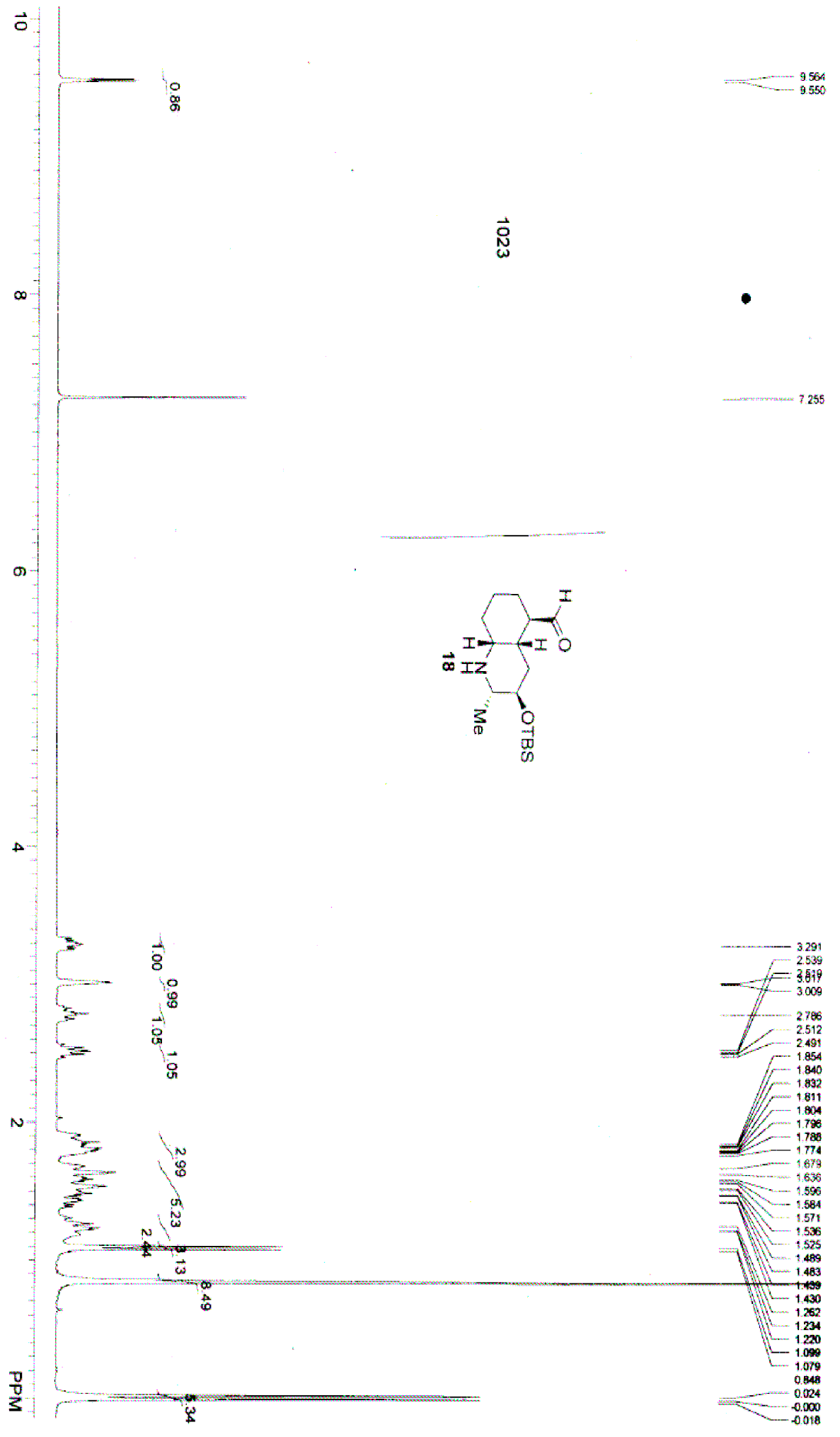




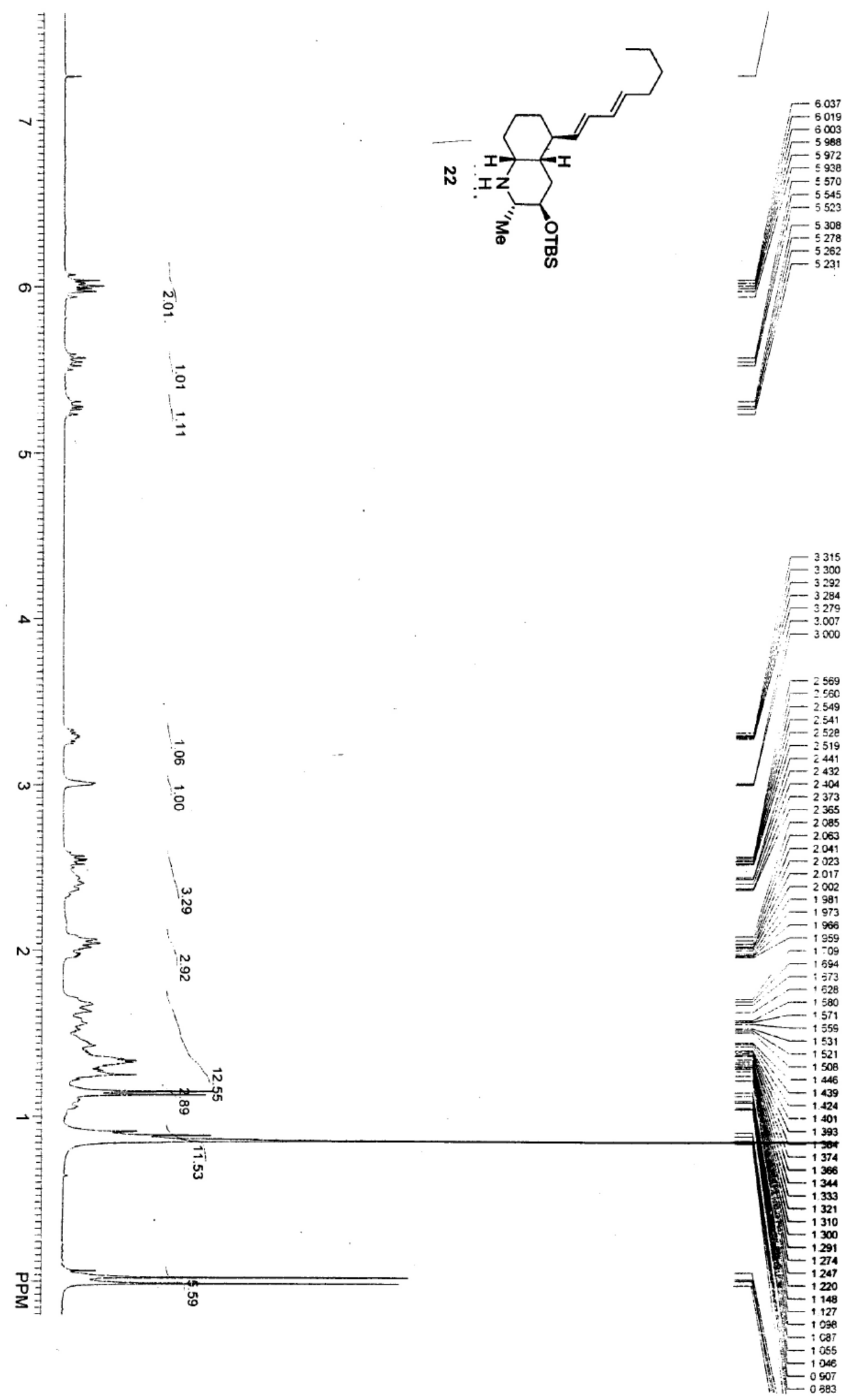



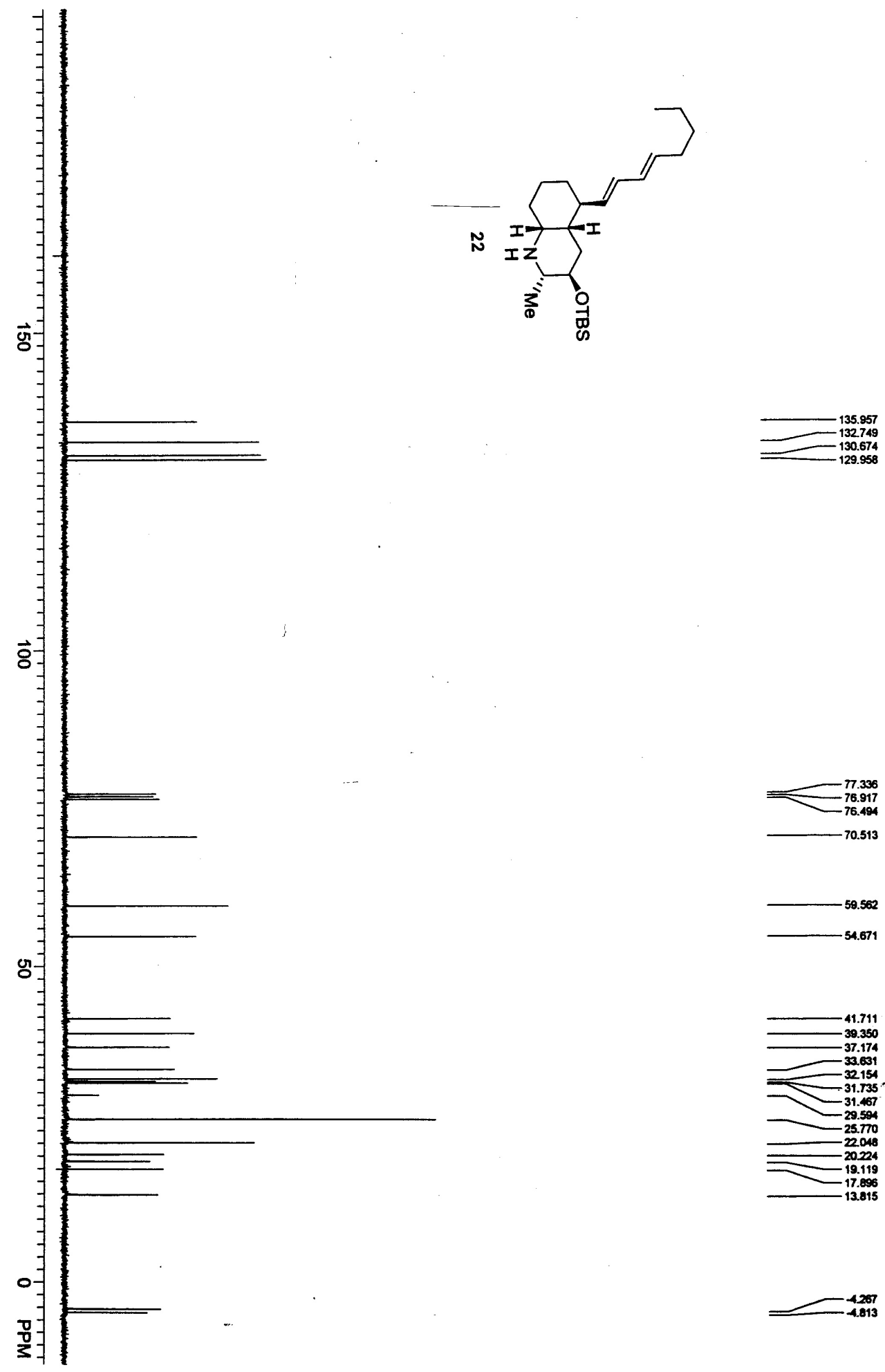


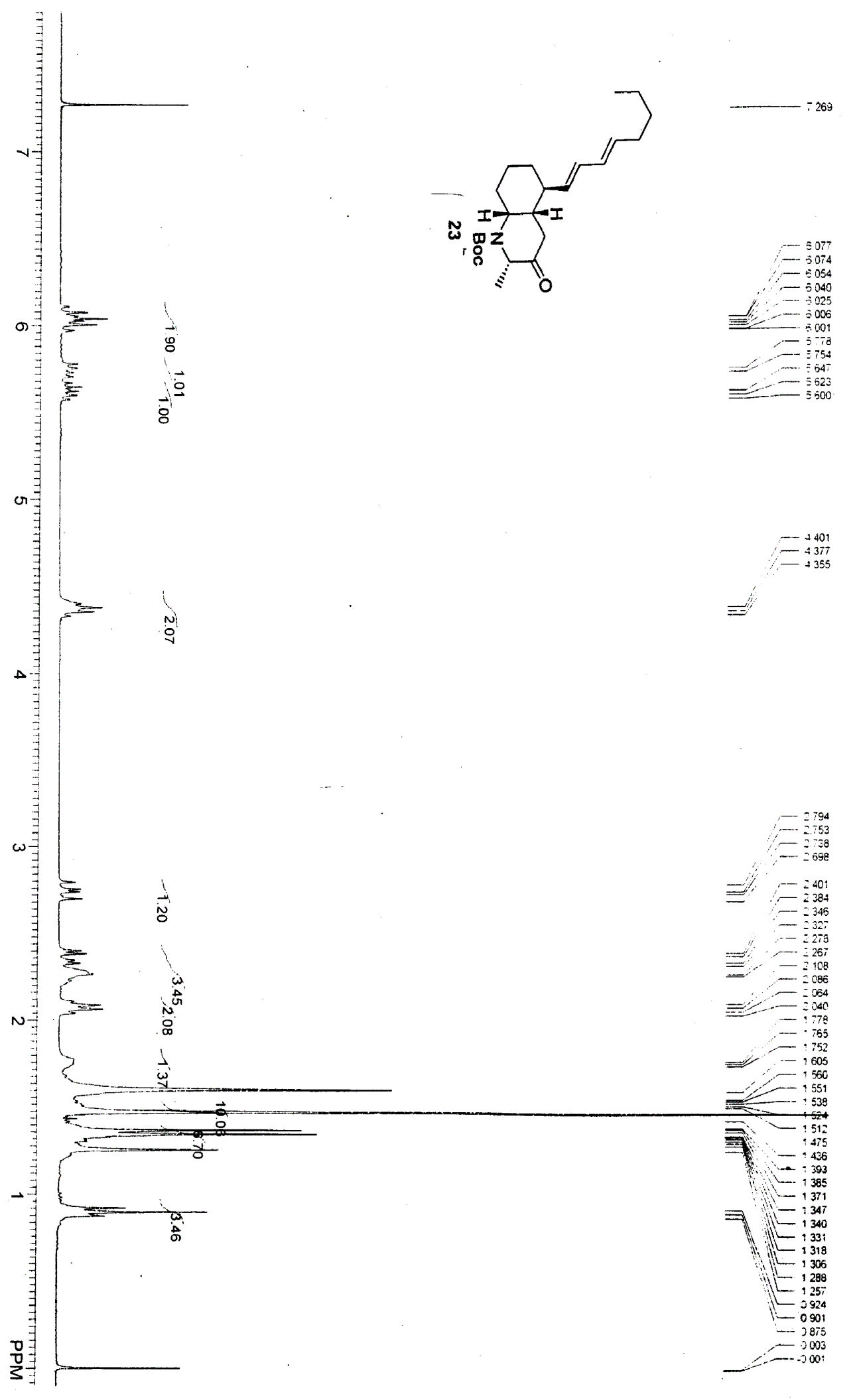



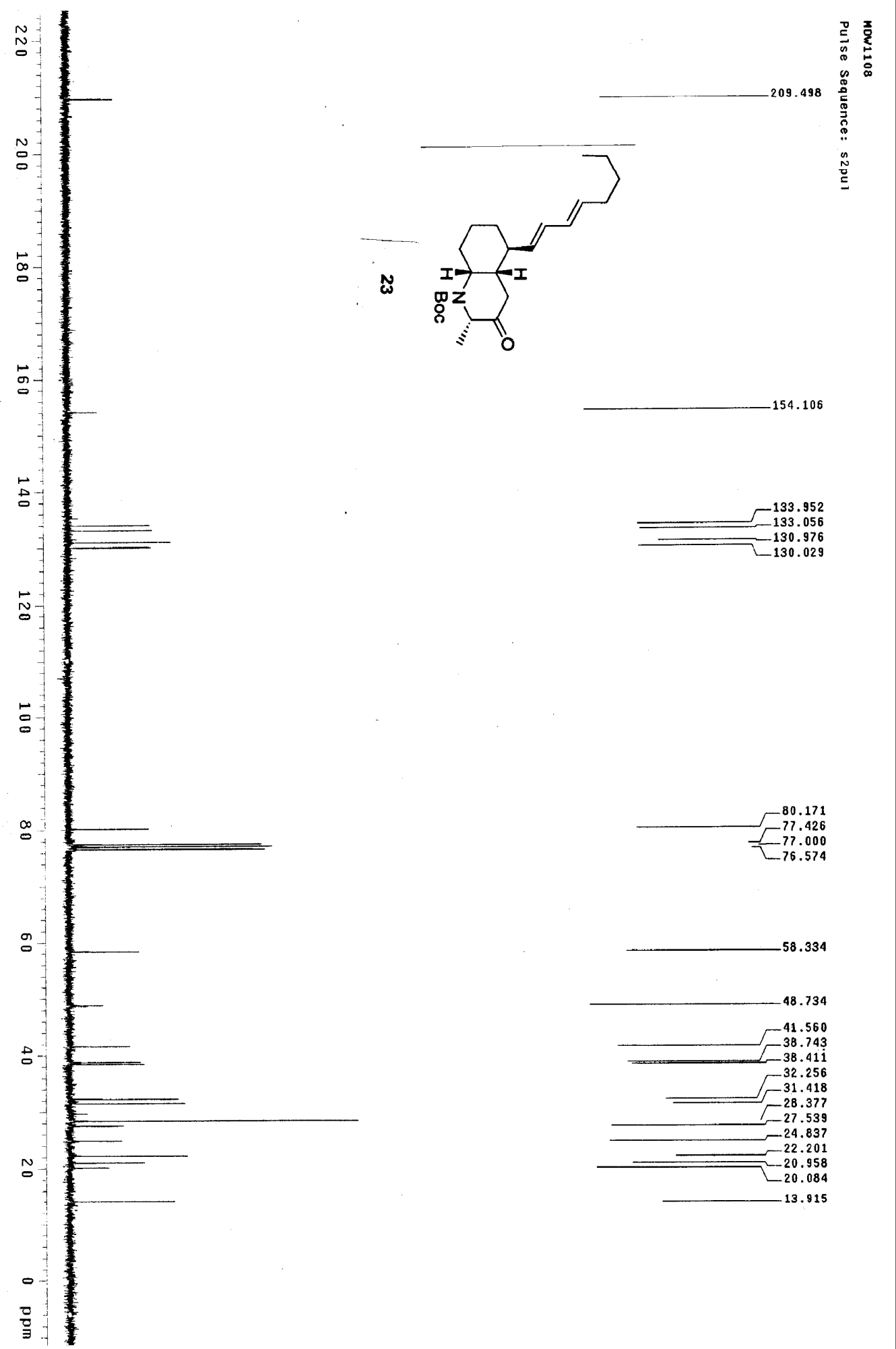


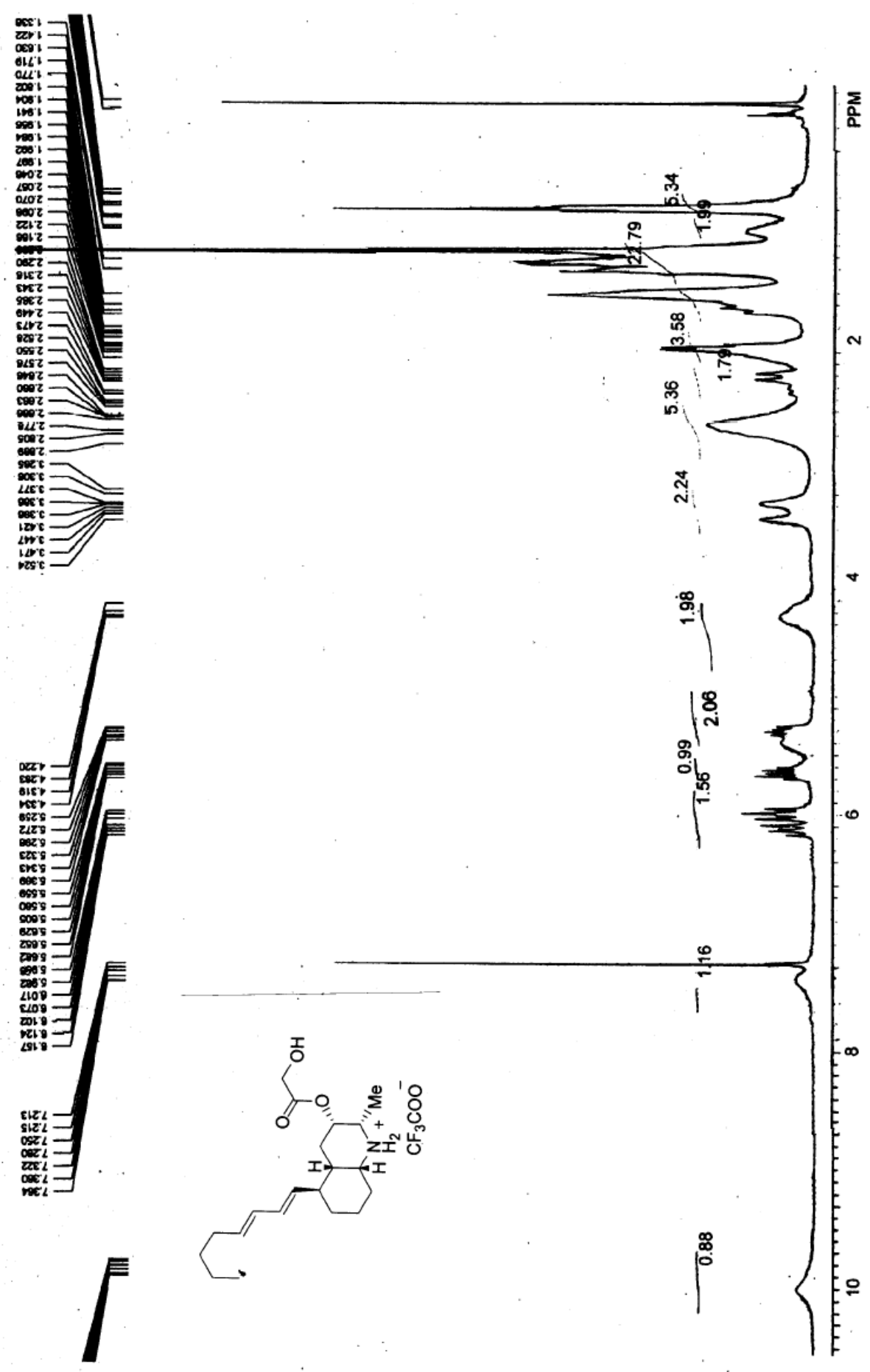

Compound 1a 


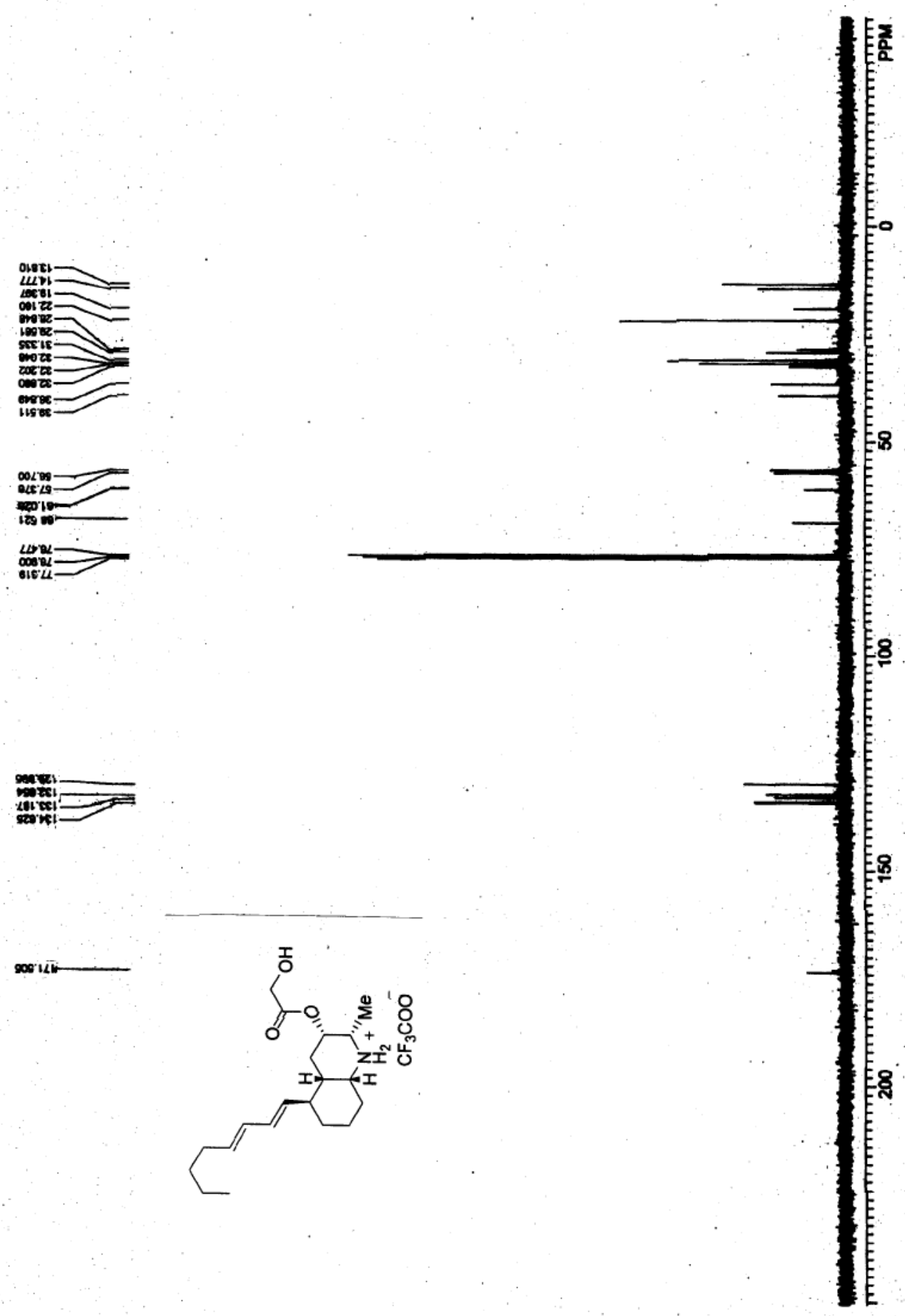

Compound 1a 


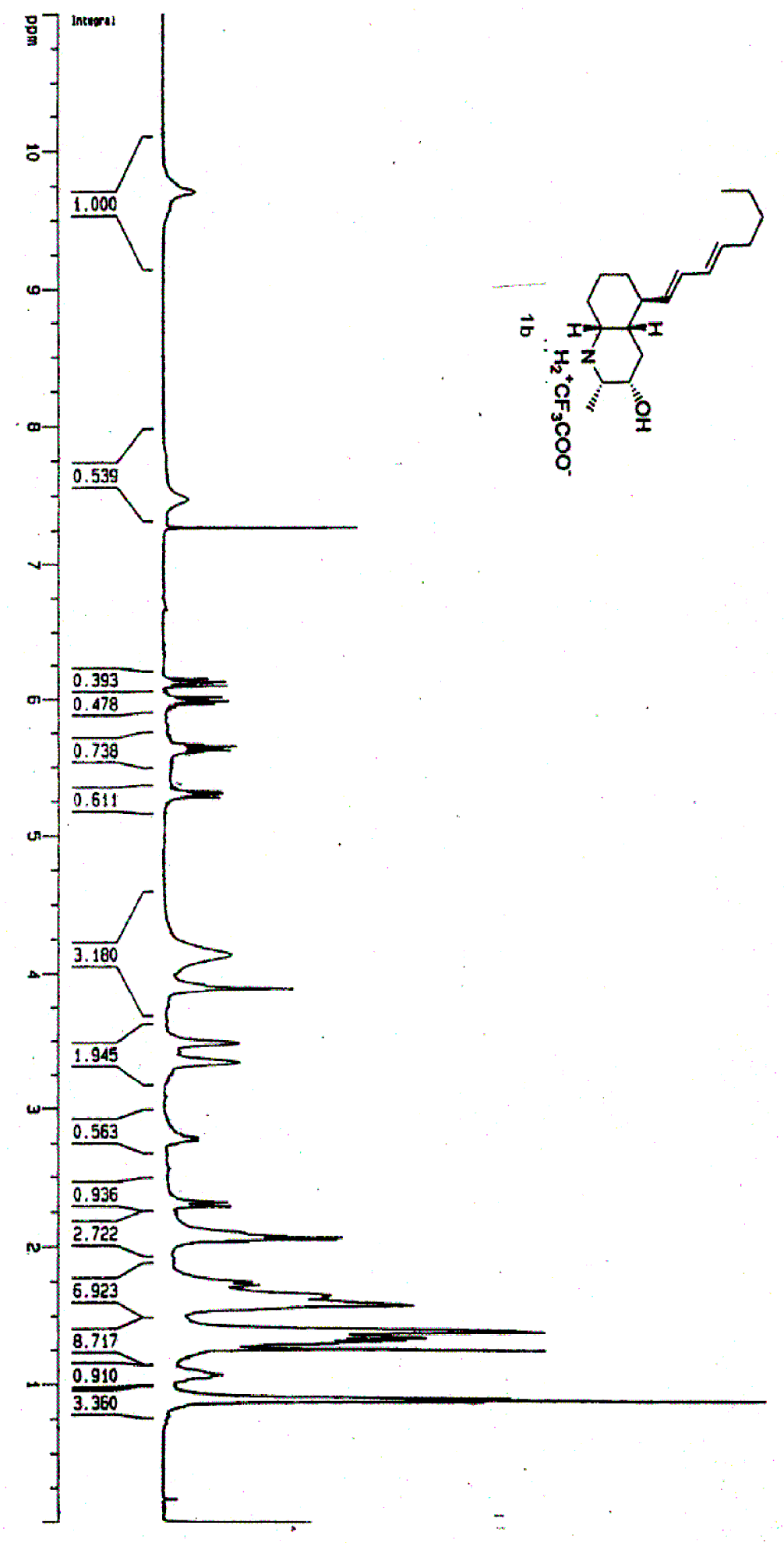

-3736.99 $-3634.10$ 3074.21 $-3063.78$ $-3058.95$ $-3048.76$ 3007.86 -2997.50 - 2992.07 $-2982.72$ 2834.45 $-2827.40$ $-2819.93$ $-2812.38$

$-2805.39$

$-2663.68$

$-2655.02$

$-2648.69$

$\mathrm{L}_{2640.00}$

$-2071.47$

1947.36

${ }^{1746.13}$ ${ }^{1675.69}$ 1398.73 $r^{-1147: 12}$ $-1043.10$ $-1036.12$

$-1029.19$ Ir 829.33 - 619.30 - 793.56 697.72 - 684.78 II 681.58

- 677.48 If 674.48 - 671.04 $-664.43$ $-657.20$

$-651.22$

628.87

$-455.34$

L 448.32

$L_{441.35}$ 


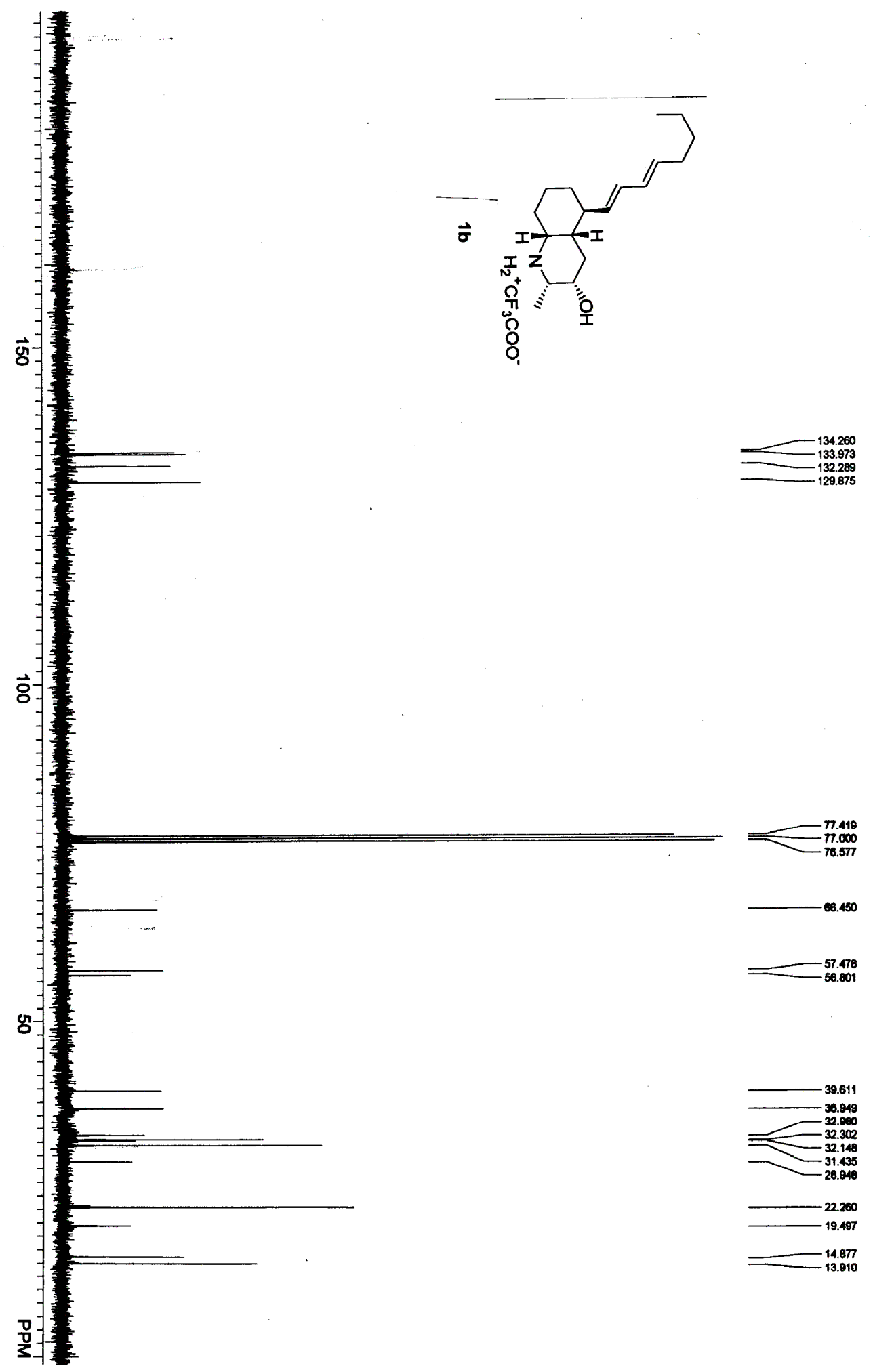




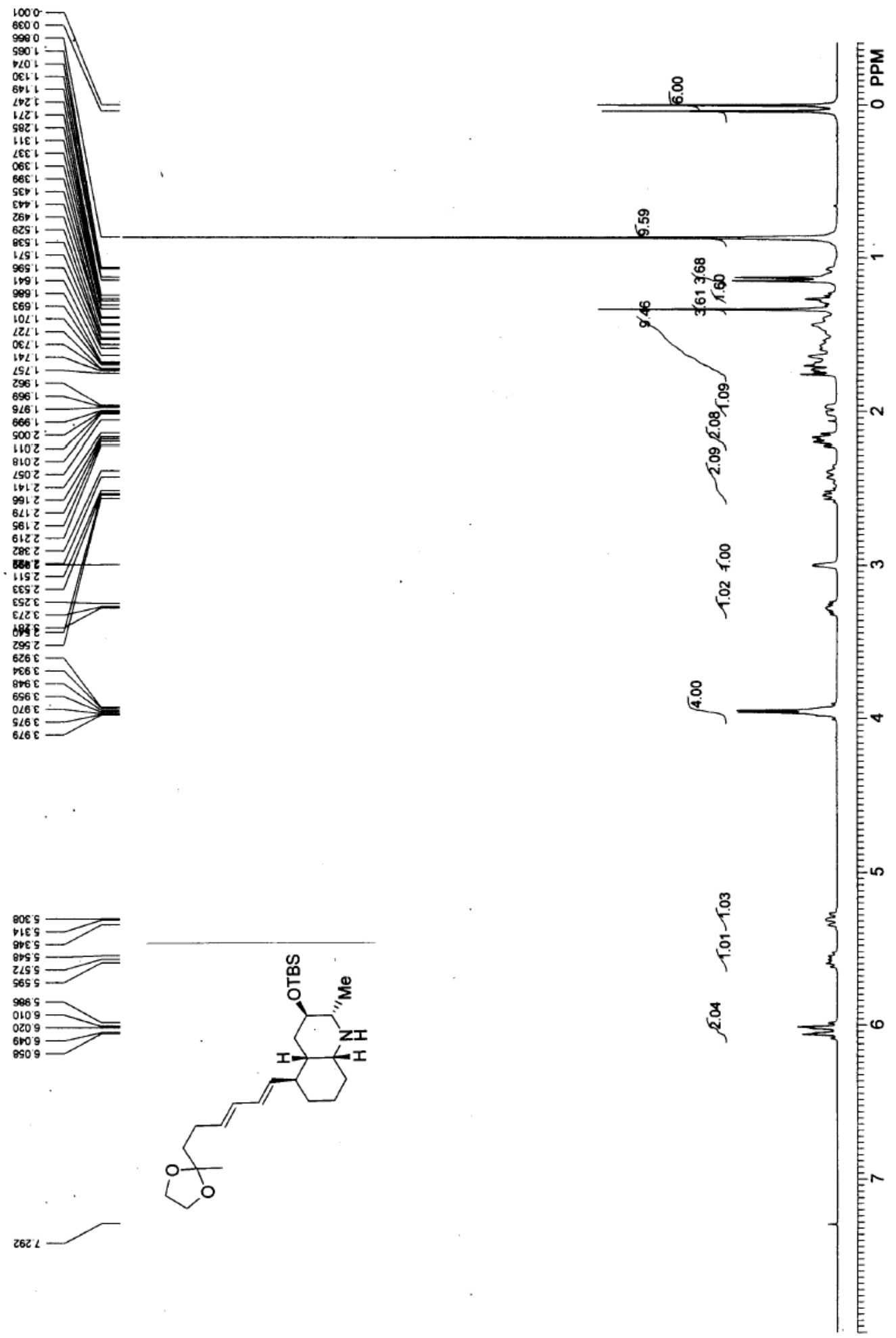

Compound 27 


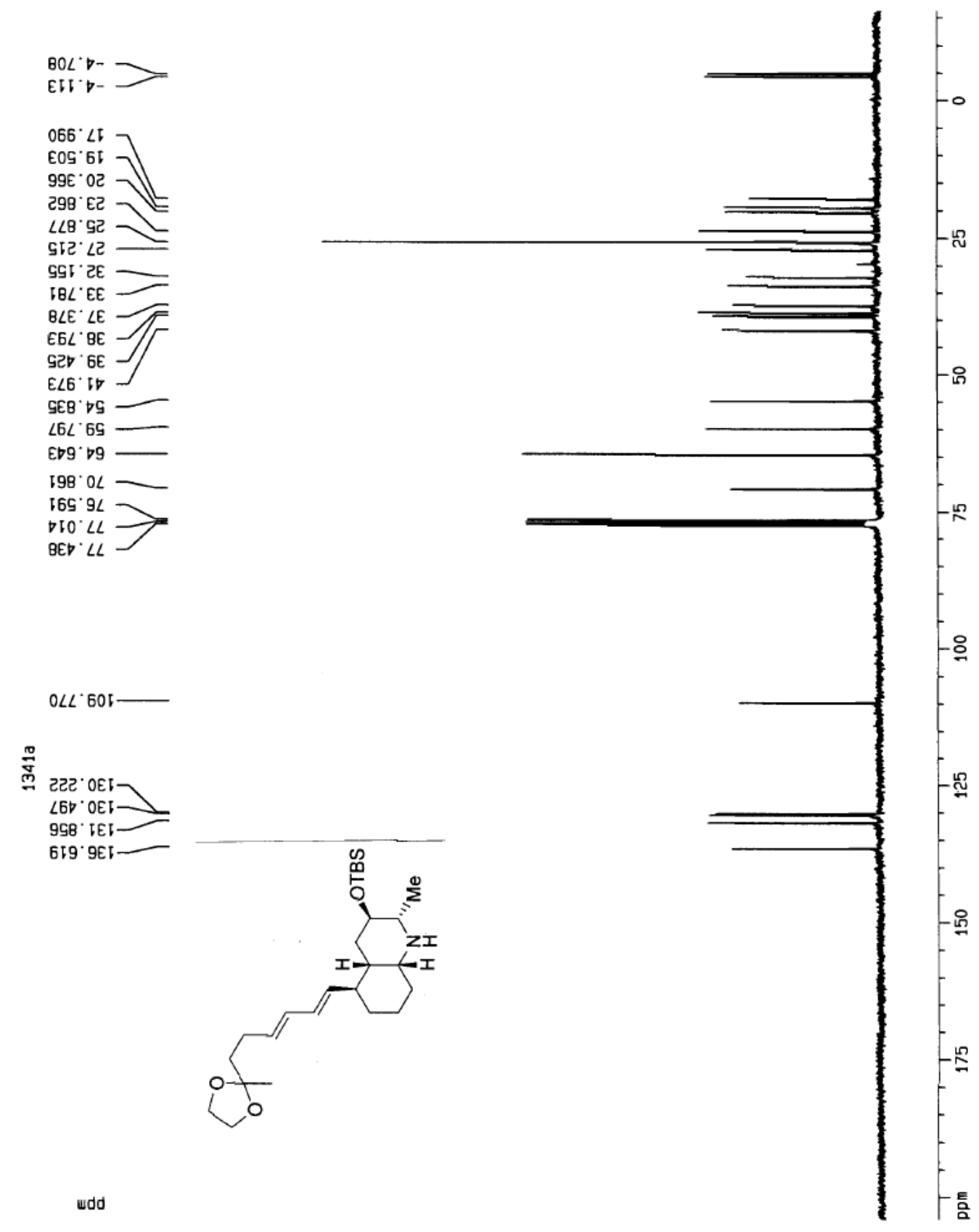

Compound 27 


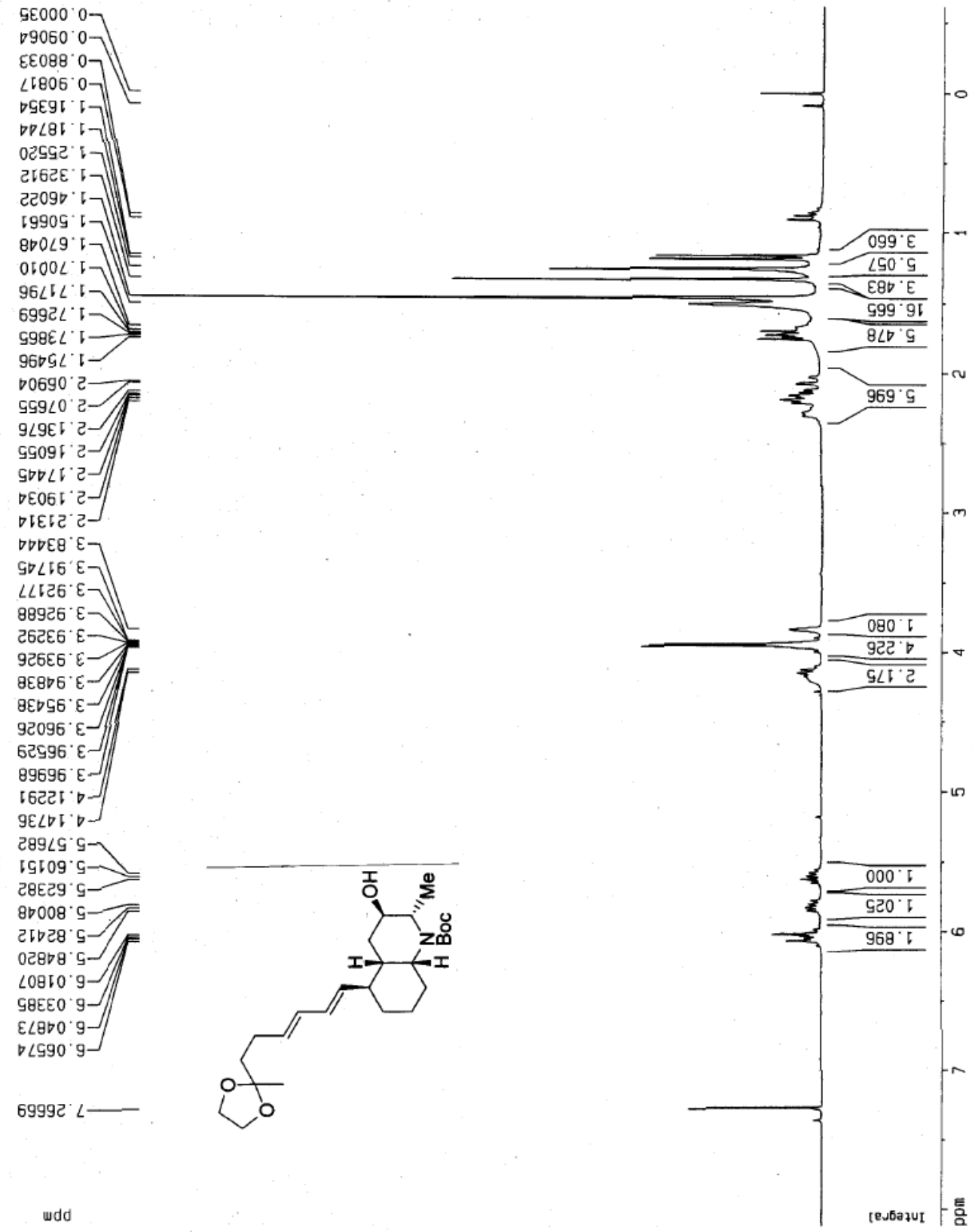

Compound 28 


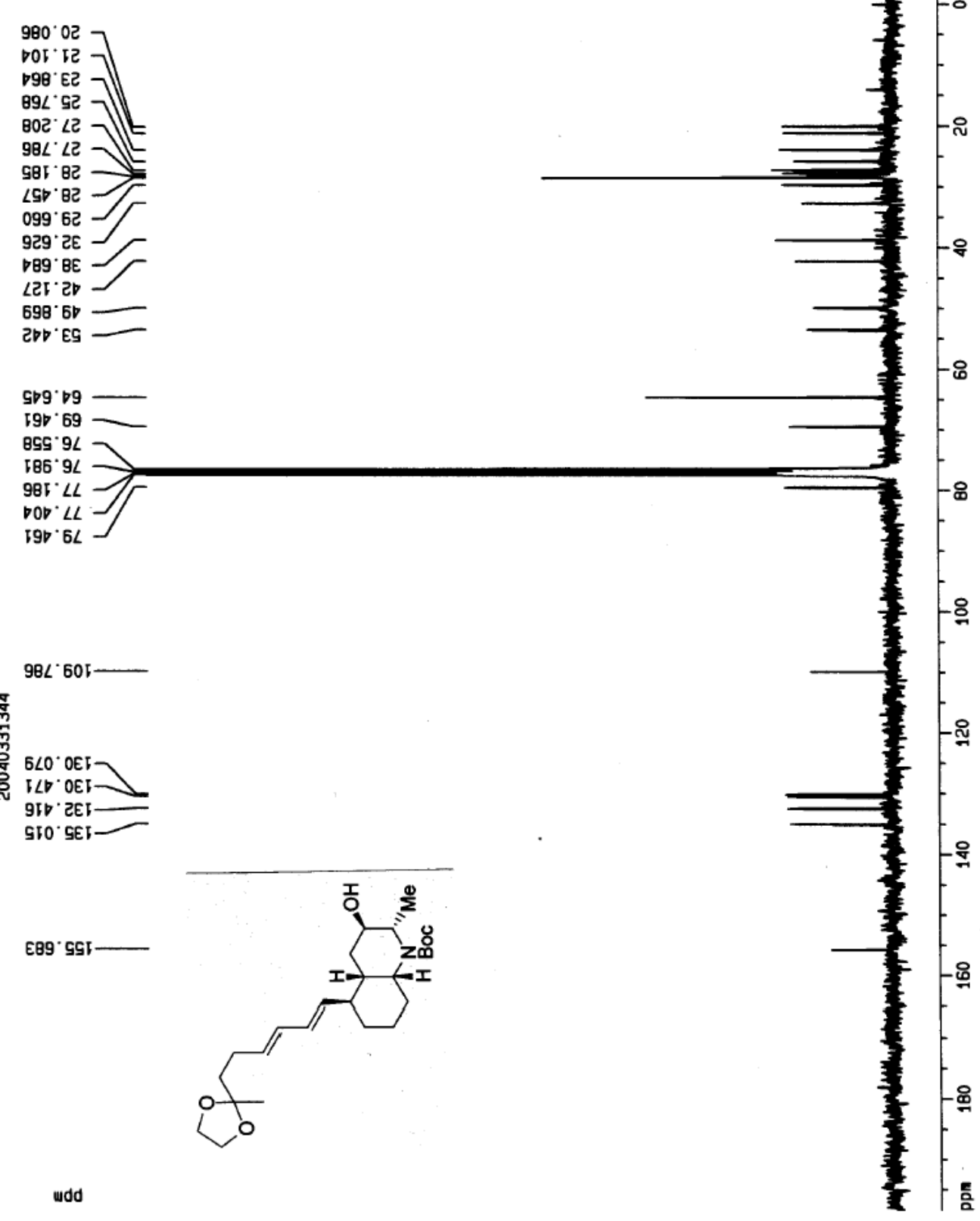

Compound 28 


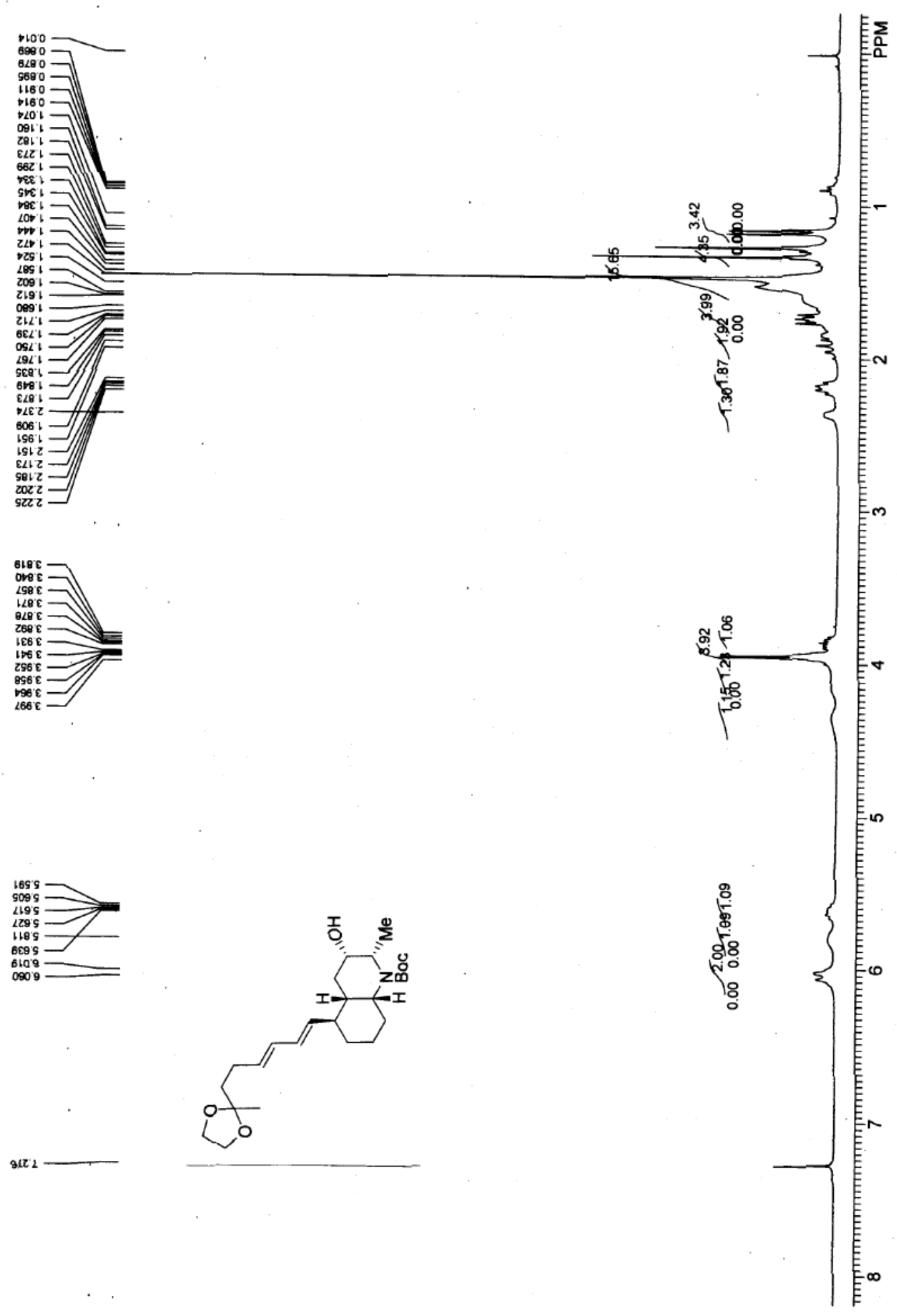

Compound 29 

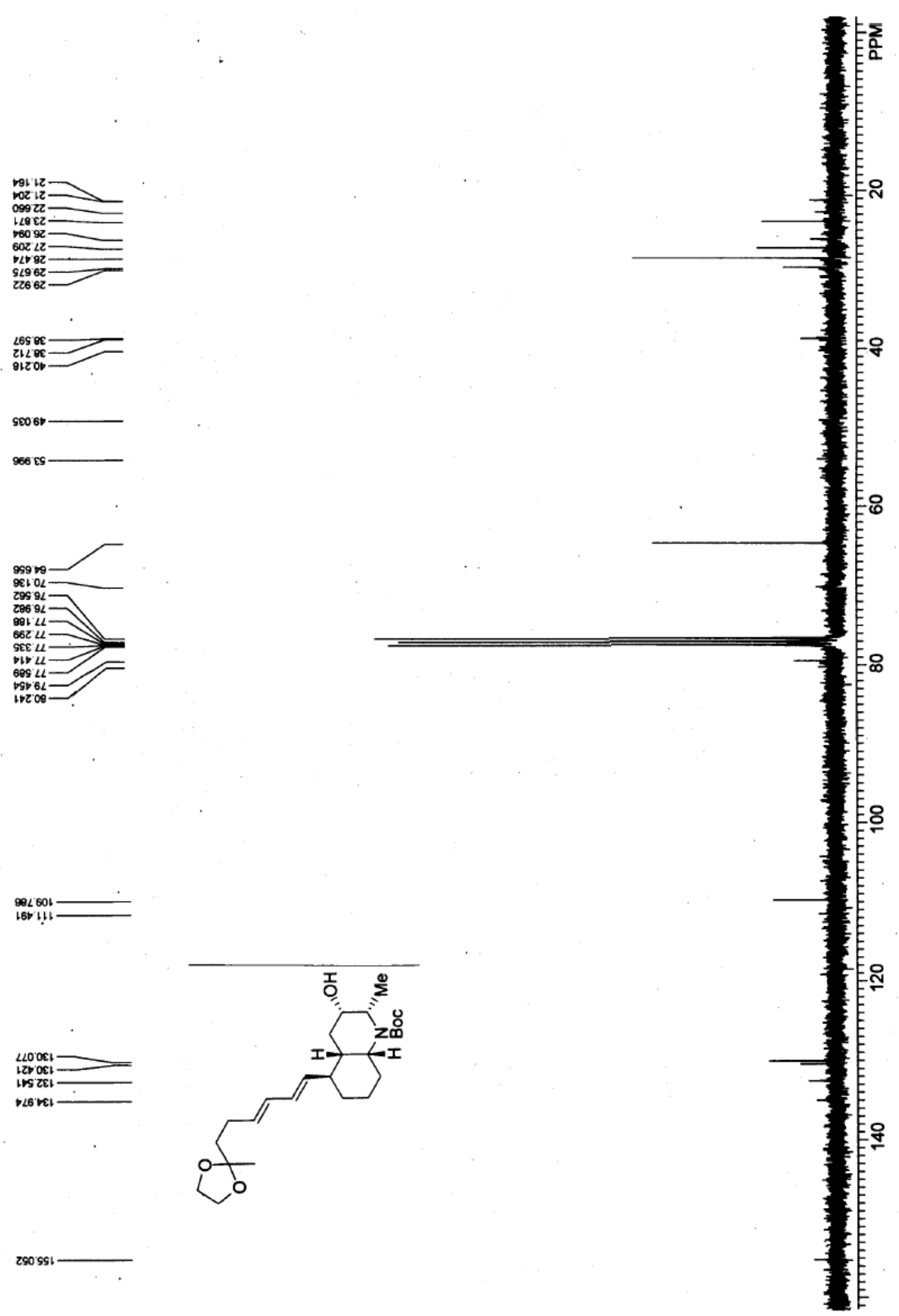

$902601-$
$16 b^{\prime} เ L !$

Compound 29 


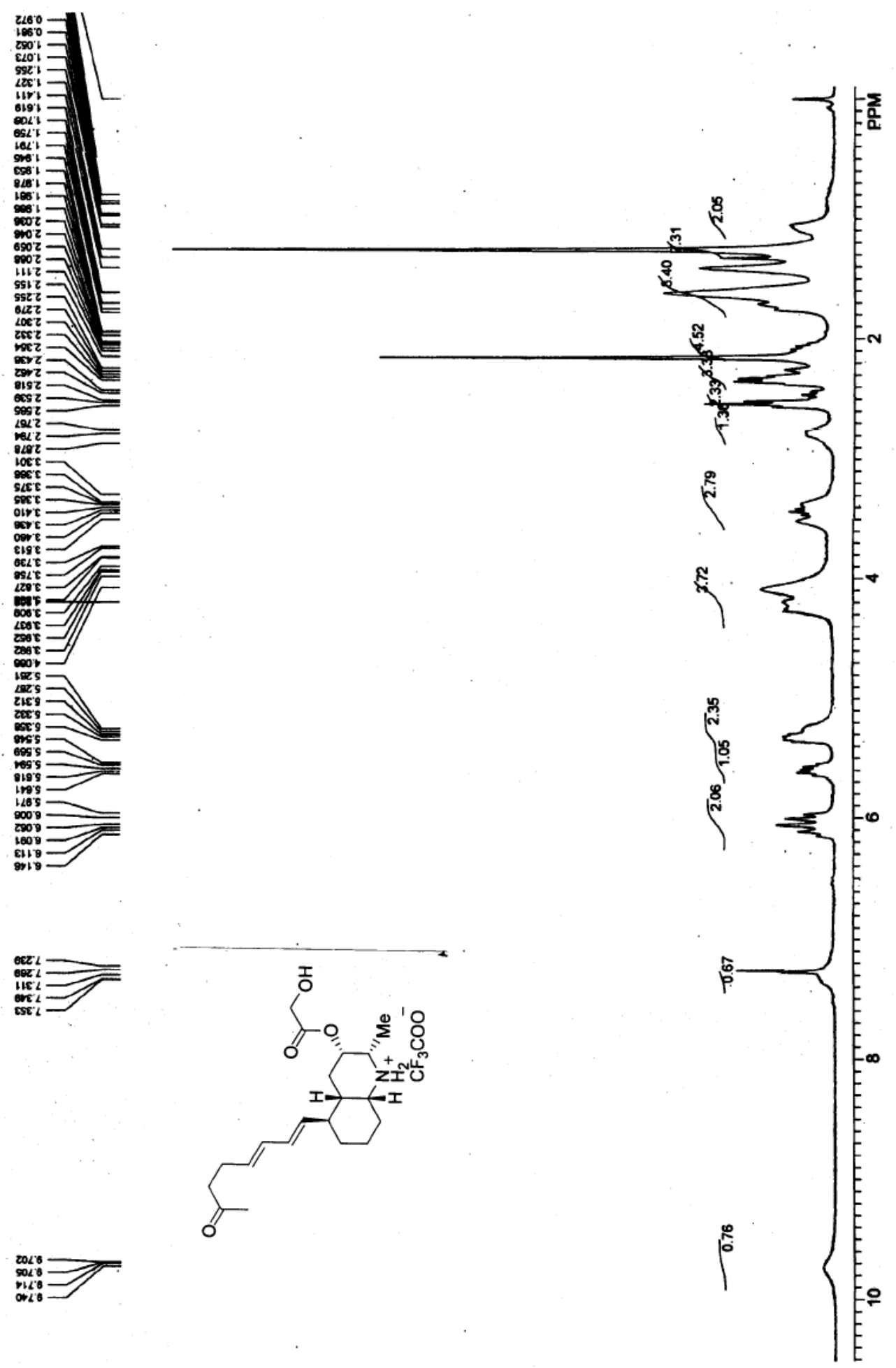

Compound 1c 


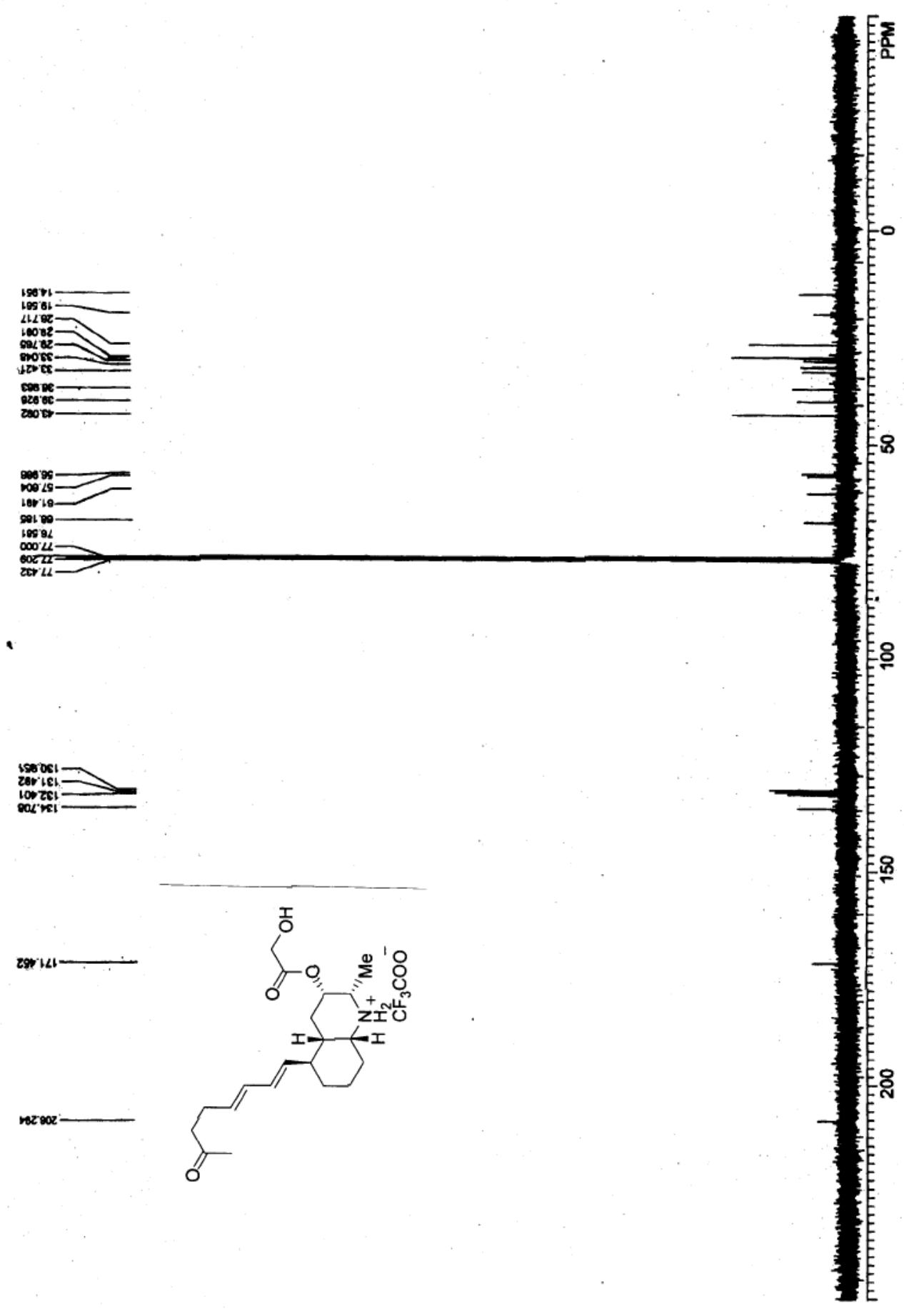

Compound 1c 


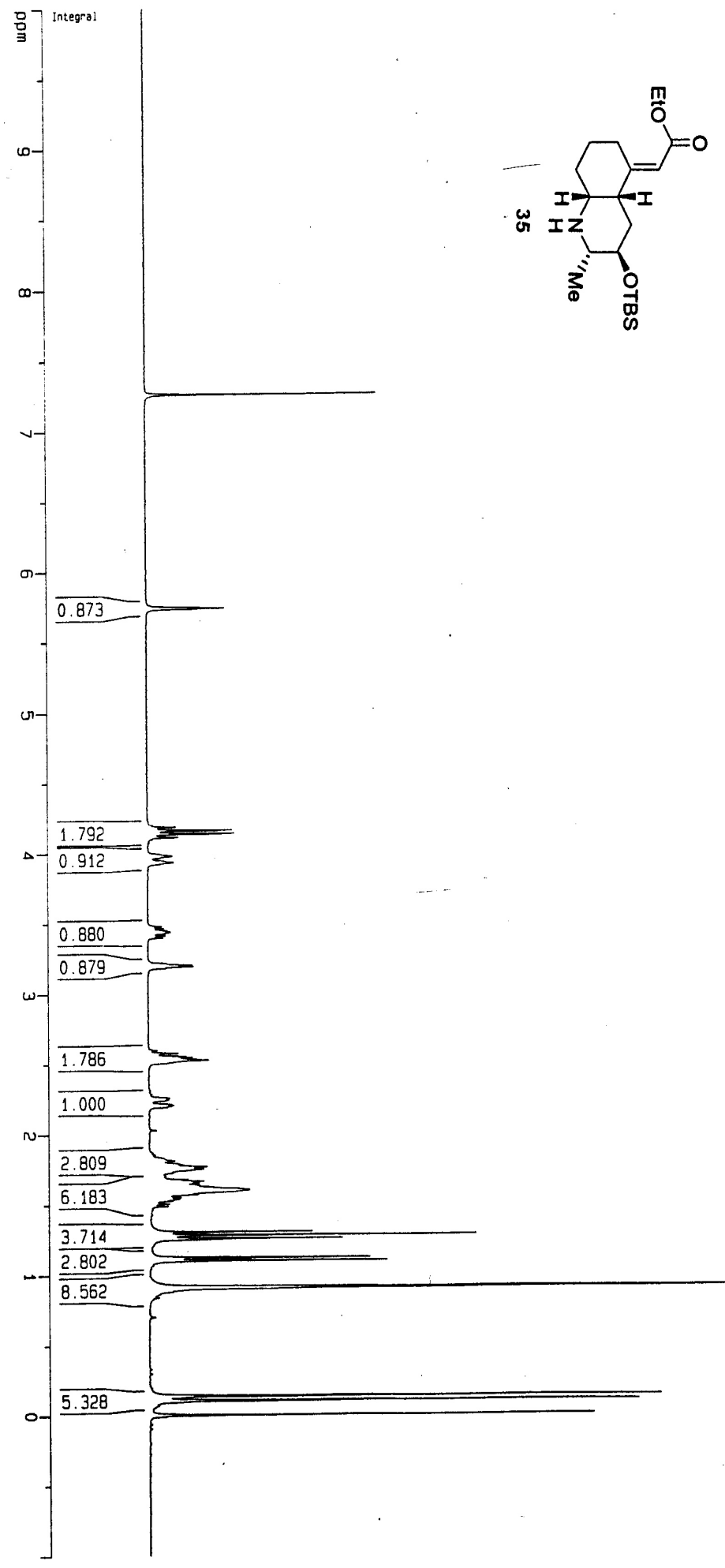

$-472.28$

- 463.45

- 461.17

I. 391.93

I. 384.81

. $\quad 377.64$

$7\left[\begin{array}{l}336.73 \\ 330.49\end{array}\right.$

$\left[\begin{array}{r}330.49 \\ 272.92\end{array}\right.$

$\left[\begin{array}{r}272.92 \\ 40.75\end{array}\right.$

L 30.94

$\frac{\cdots}{a} \sum^{\infty} \cdots$ 

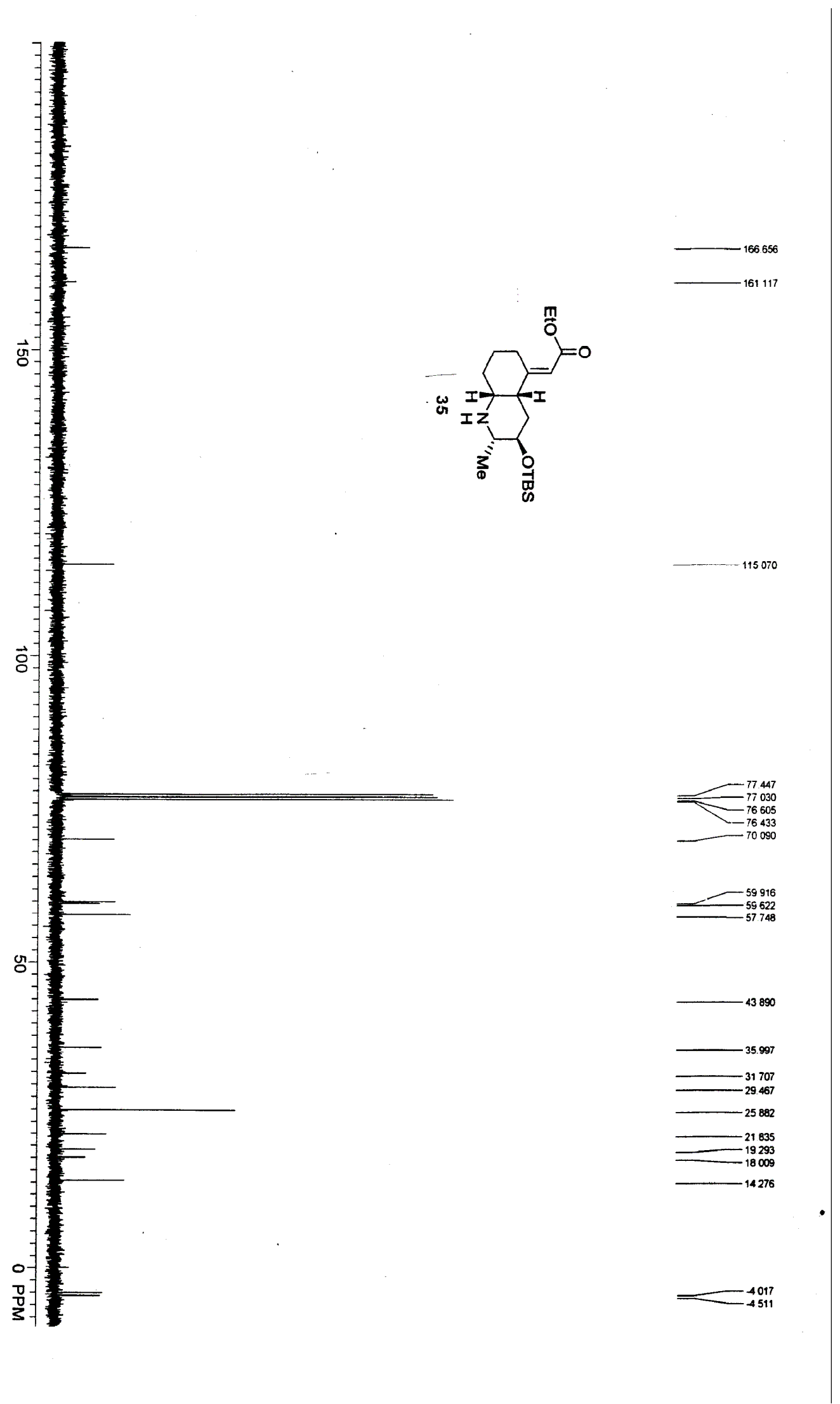


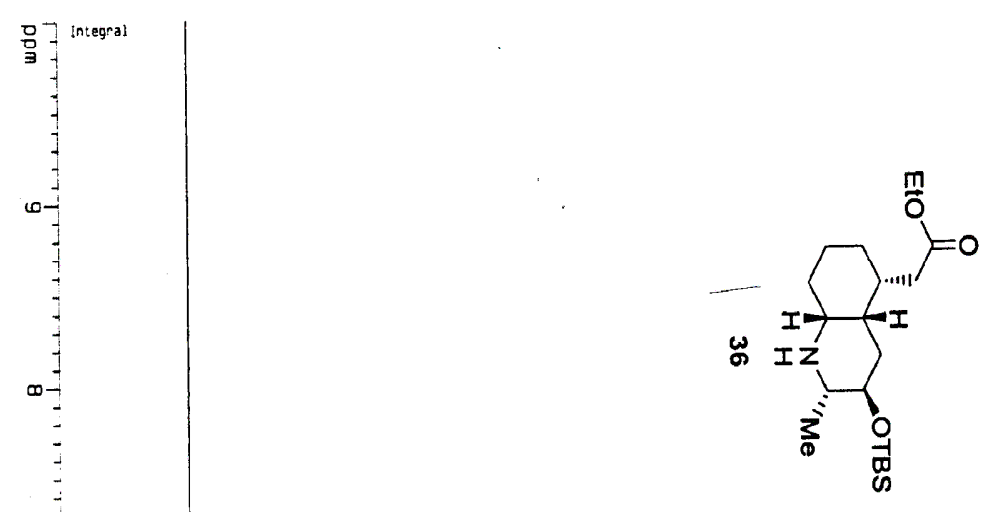

$-2170.6:$

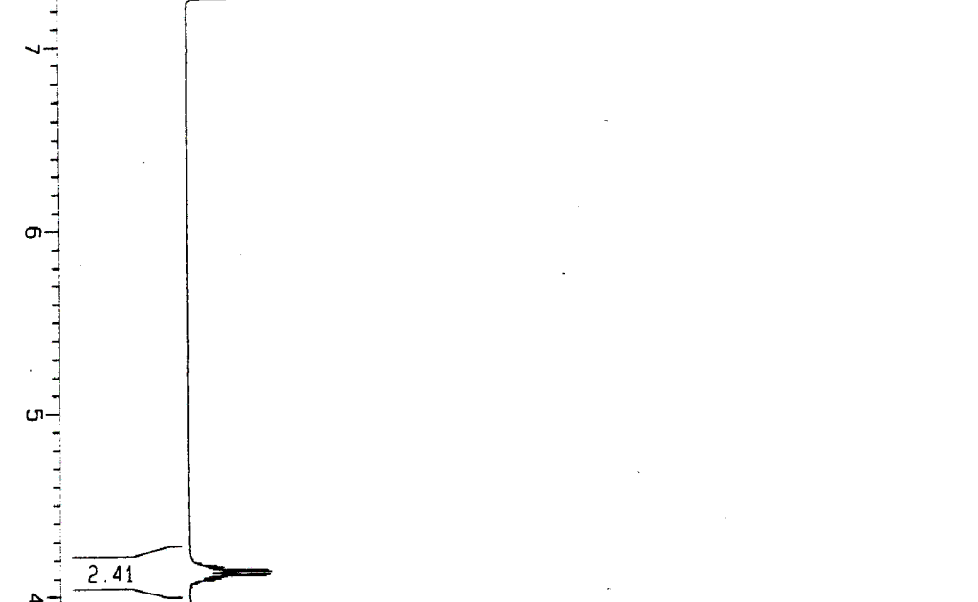

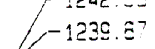

$-1235.45$

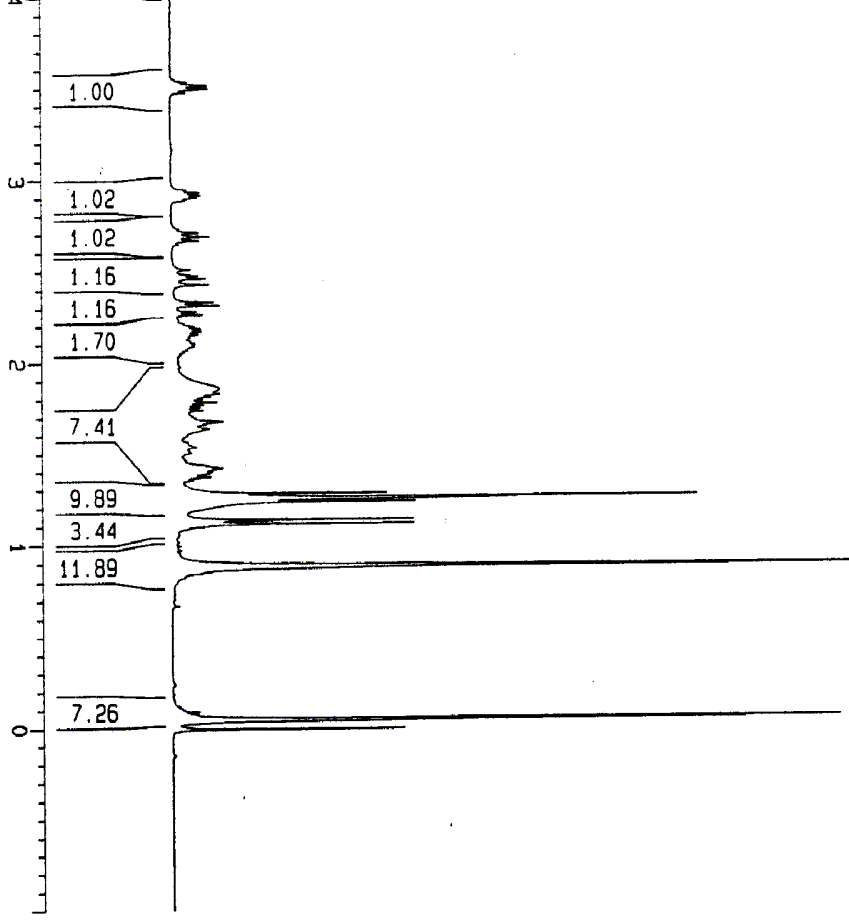

- $695.6 \mathrm{~s}$

- 54E.C:

r 503.29

$\int$ 42E.E:

r 383.65 376.47

$-374.73$ $369 . \pm 3$

$-340.32$

- 333.E4

ᄂ 272.52

- 264.E?

13.73

$\left\{\begin{array}{l}13.73 \\ -1.73\end{array}\right.$

$-12.9$ 

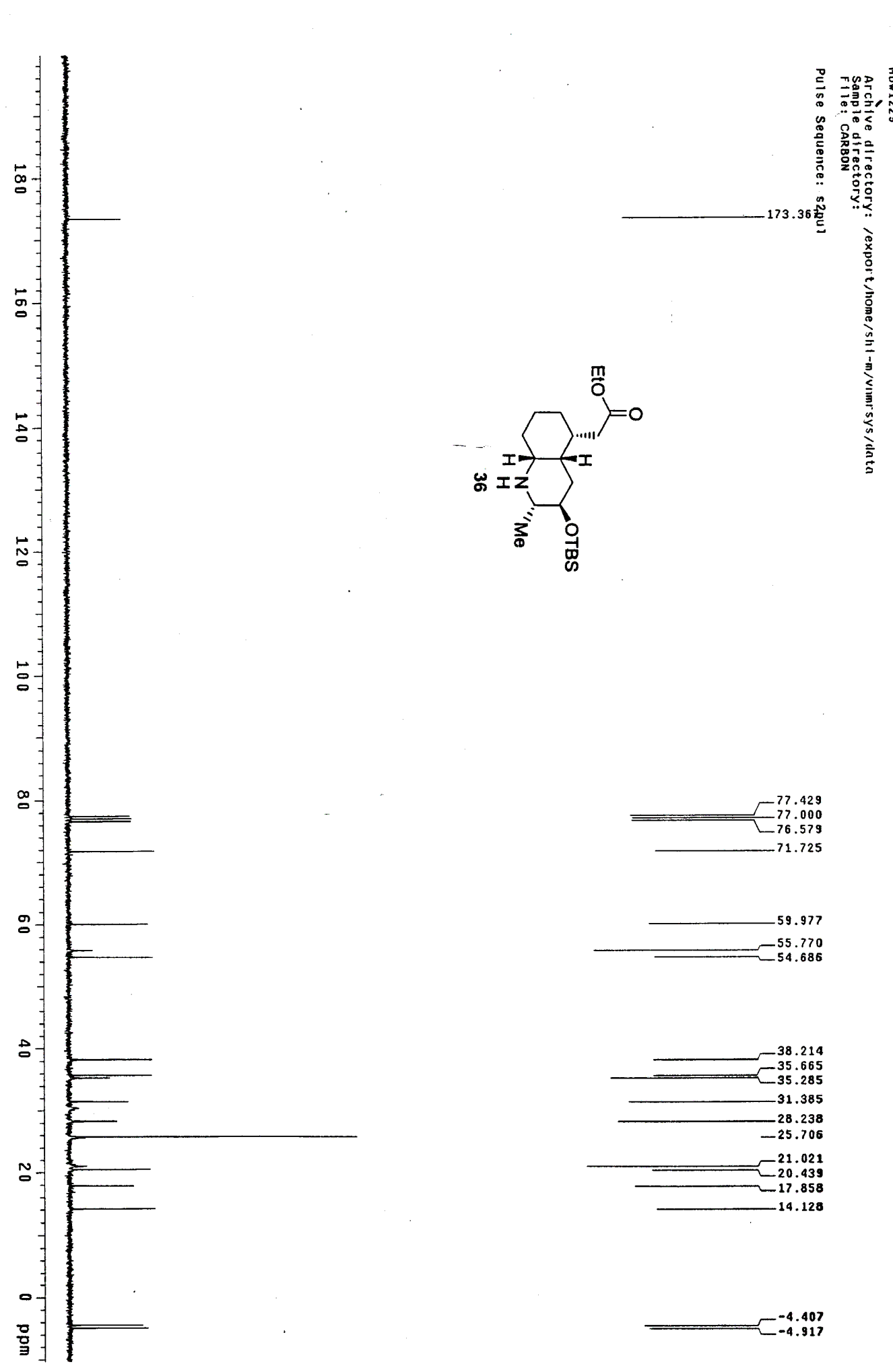


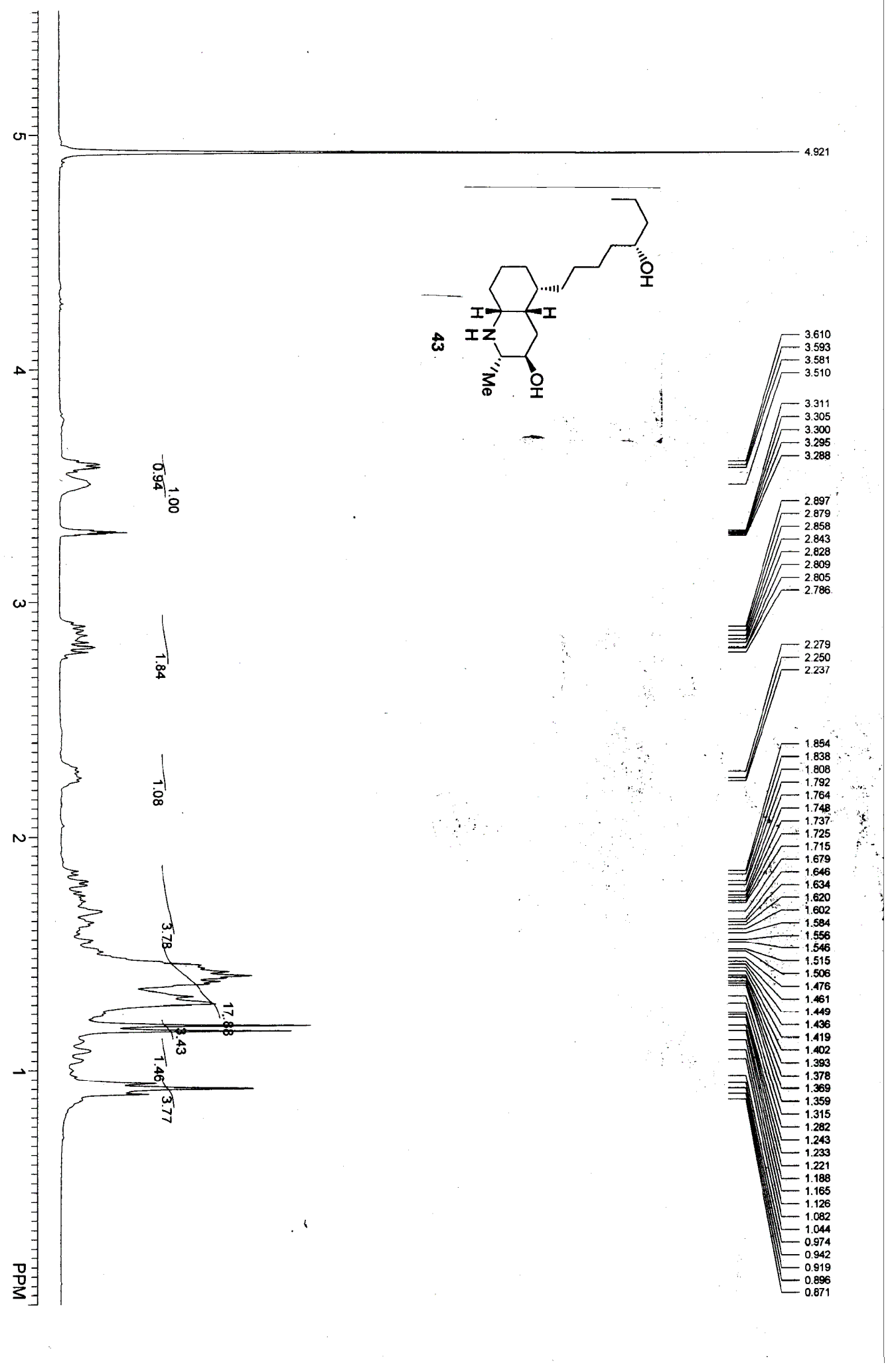




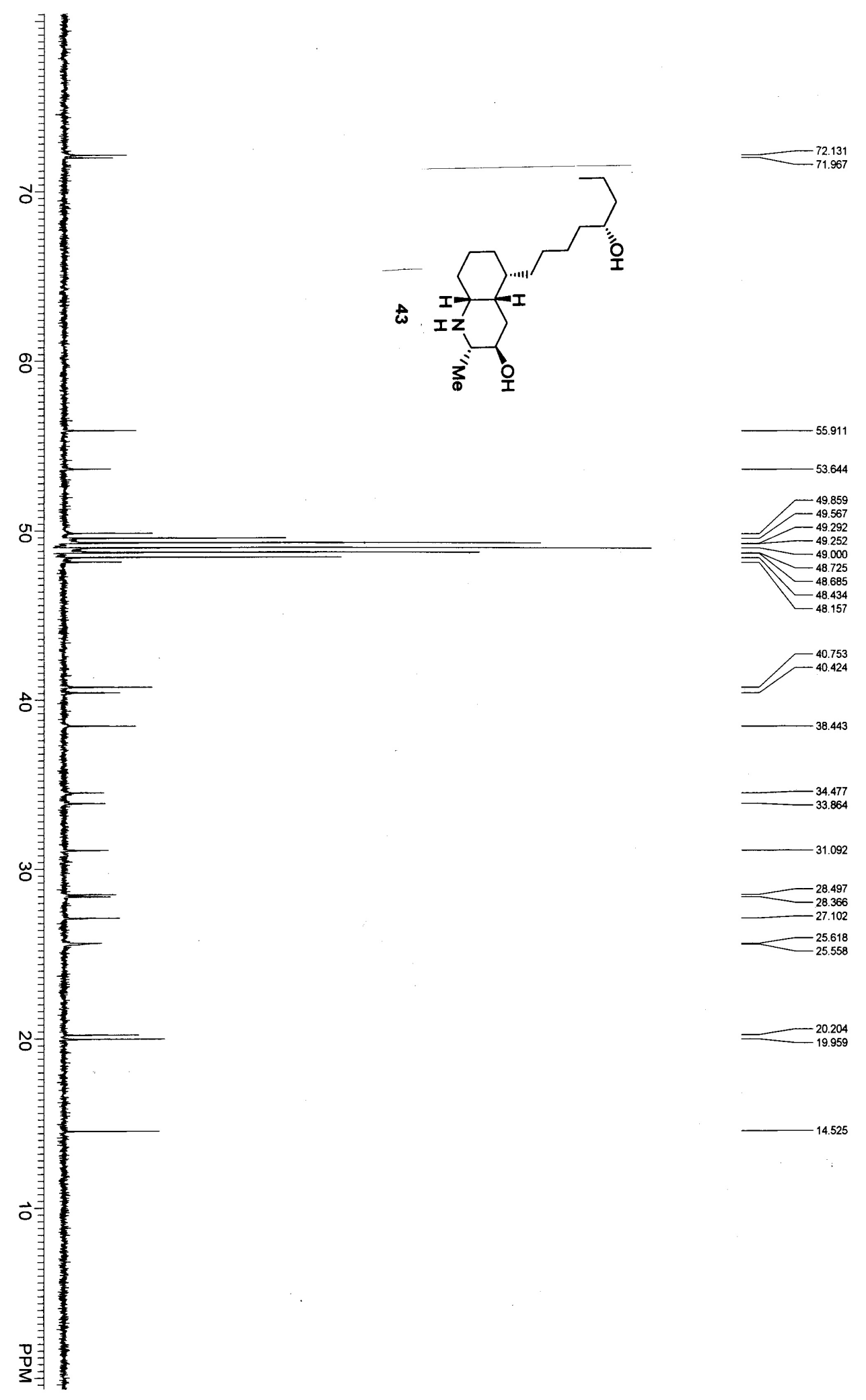




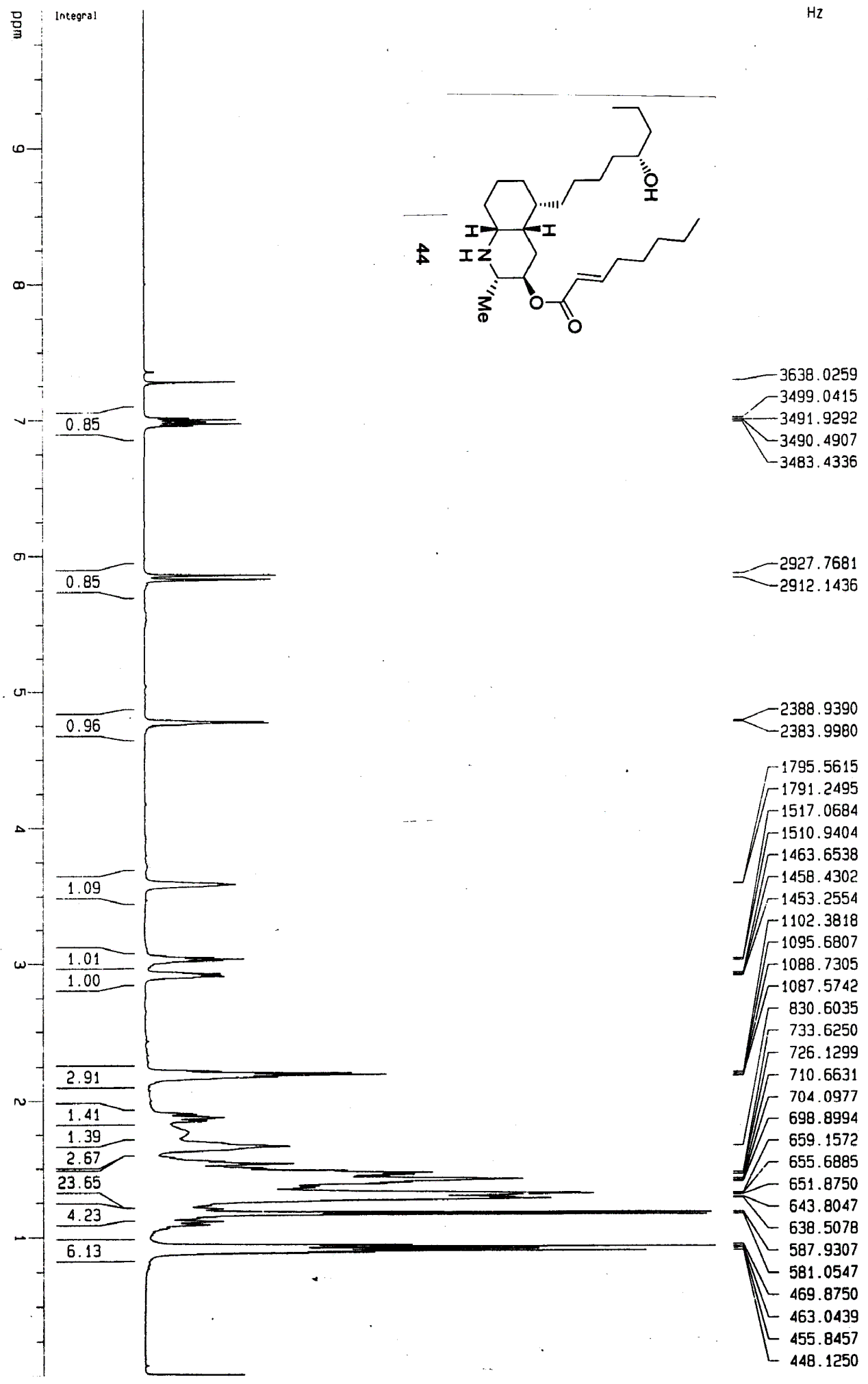



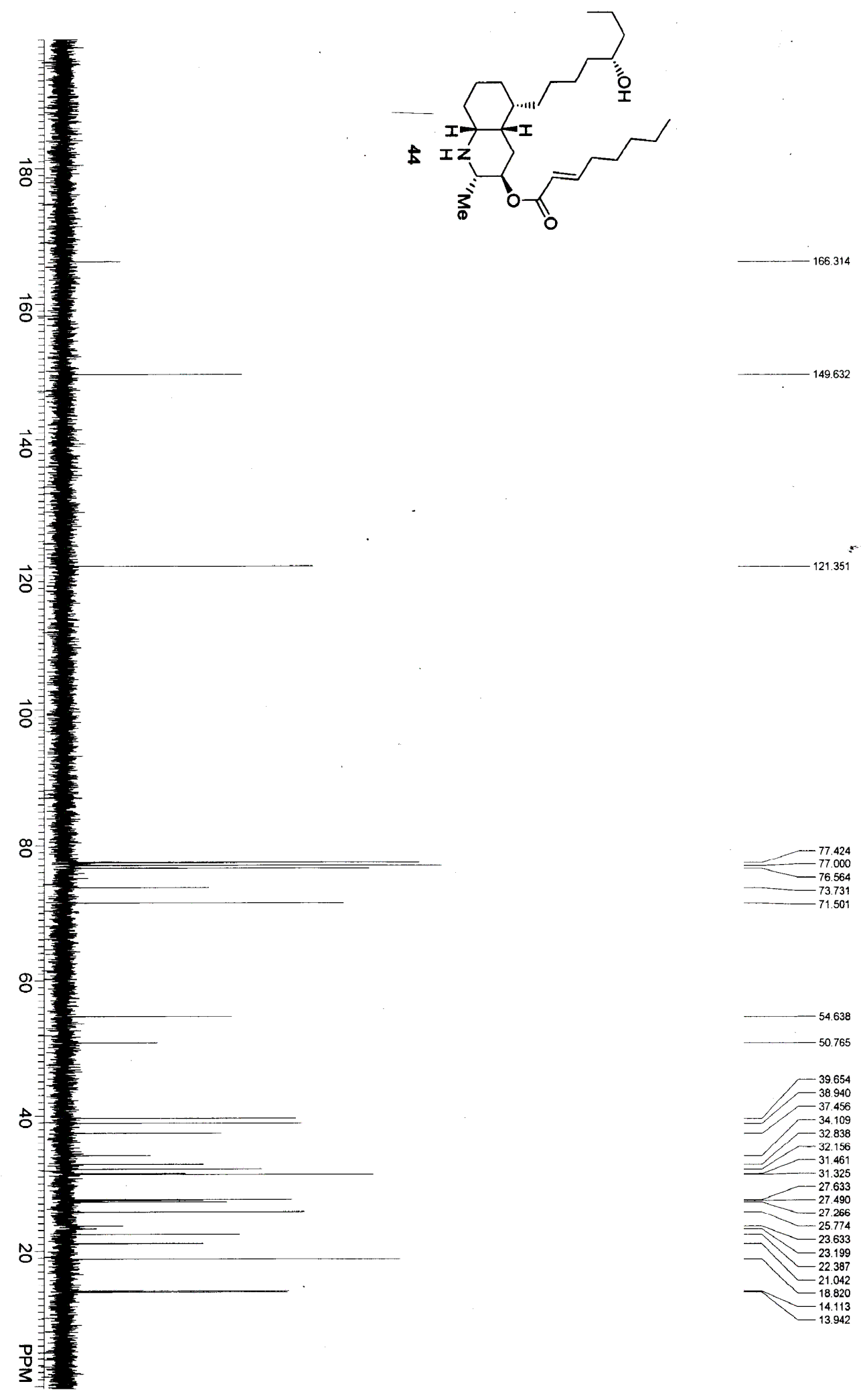

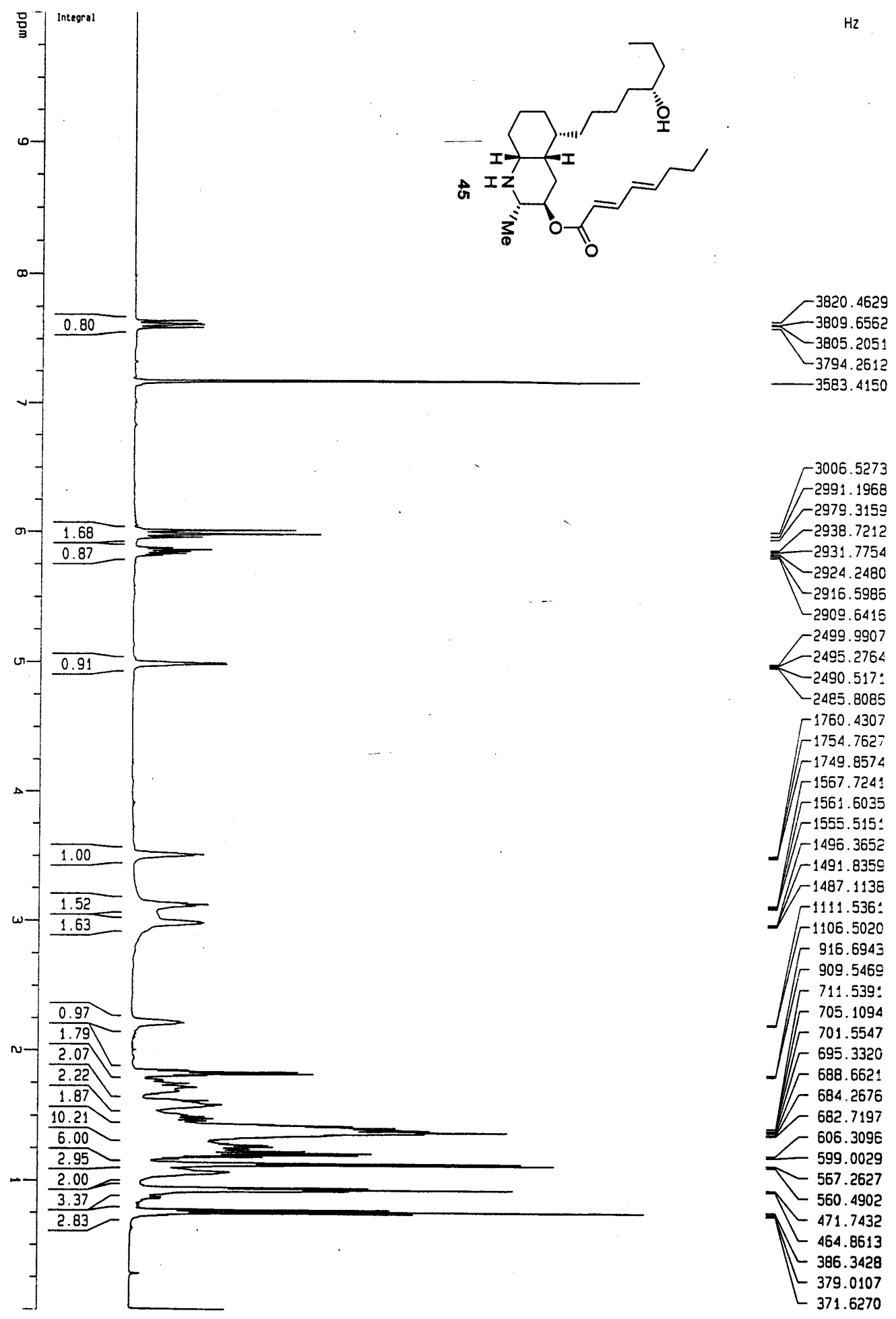

3006.5273

2991.1968

2979.3159

-2938.7212

2931.7754

$-2924.2480$

$-2916.5986$

-2909.6415

2499.9907

$-2495.2764$

-2490.517 :

$-2485.8085$

1760.4307

$r^{1754.7627}$

$-1749.8574$

$-1567.724 !$

$-1561.6035$

-1555.515:

] 1496.3652

-1491.8359

$-^{1487.1138}$

\$111.536:

$\$ 1106.5020$

916.6943

909.5469

(I $711.539:$

- 705.1094

] 701.5547

F 695.3320

] 688.6621

- 684.2676

- 682.7197

- 606.3096

599.0029

567.2627

$\backslash 560.4902$

$7-471.7432$

$L_{464.8613}$

- $386.3428 \rightarrow$

$-379.0107$

371.6270

- .1 


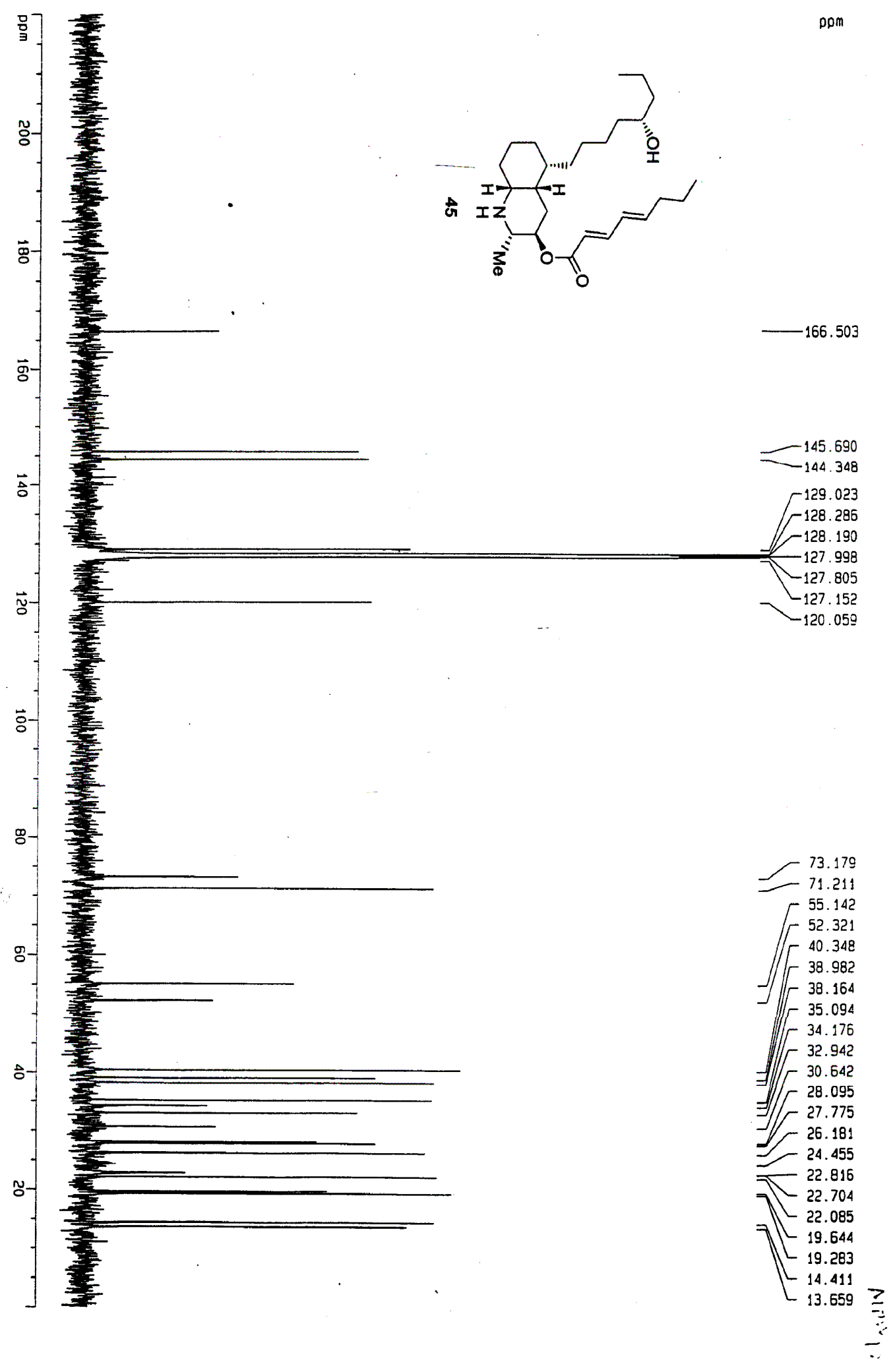




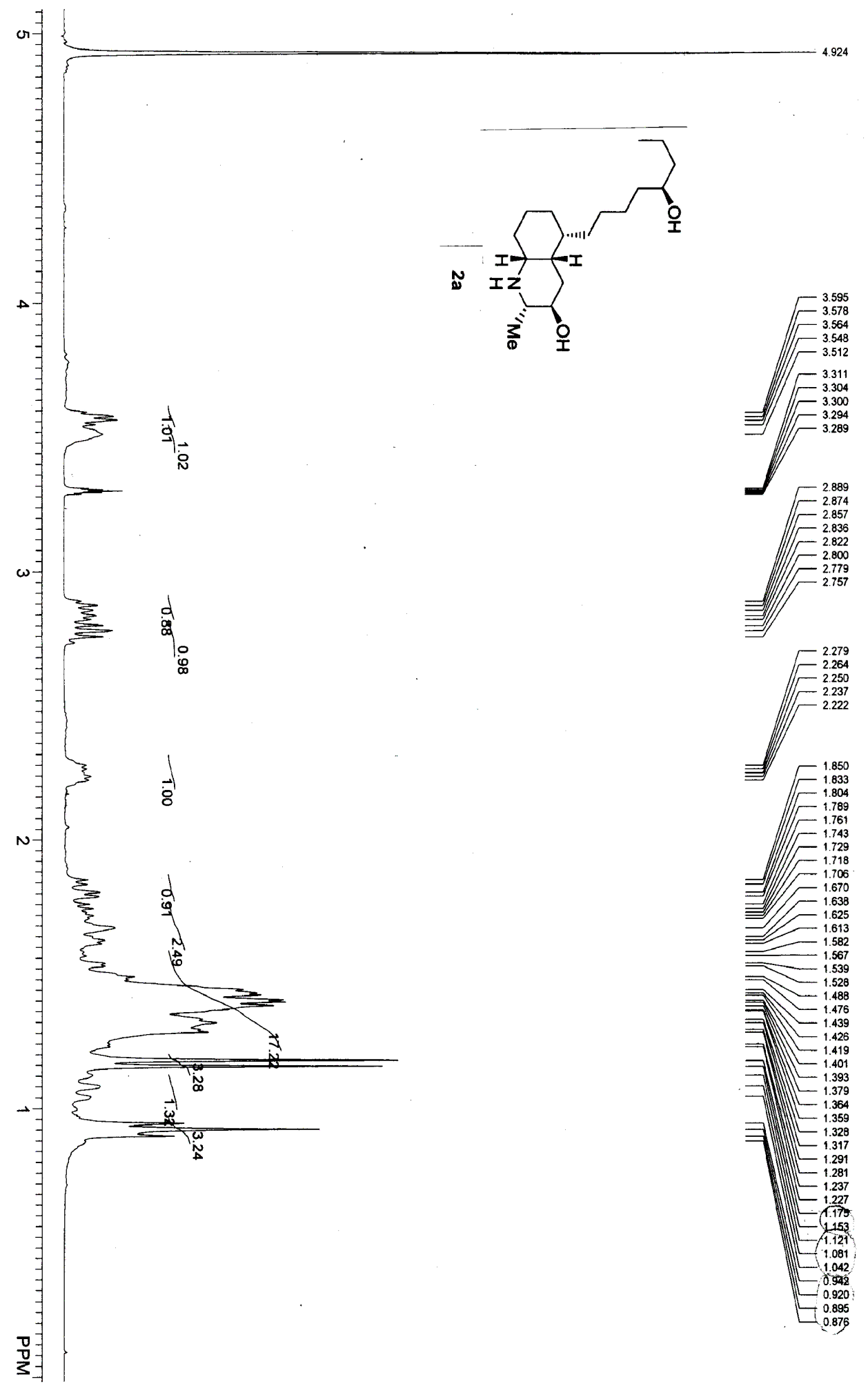




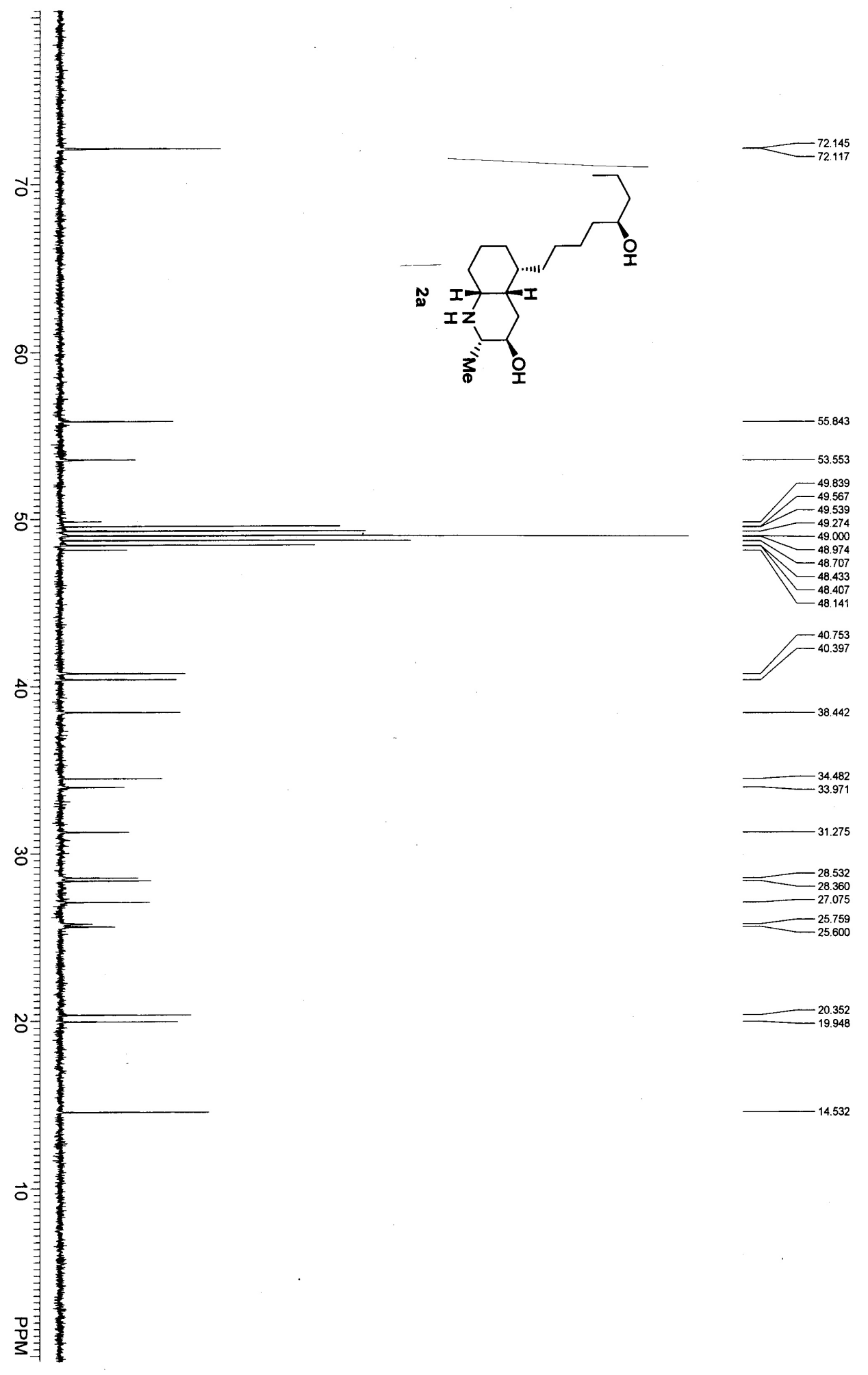




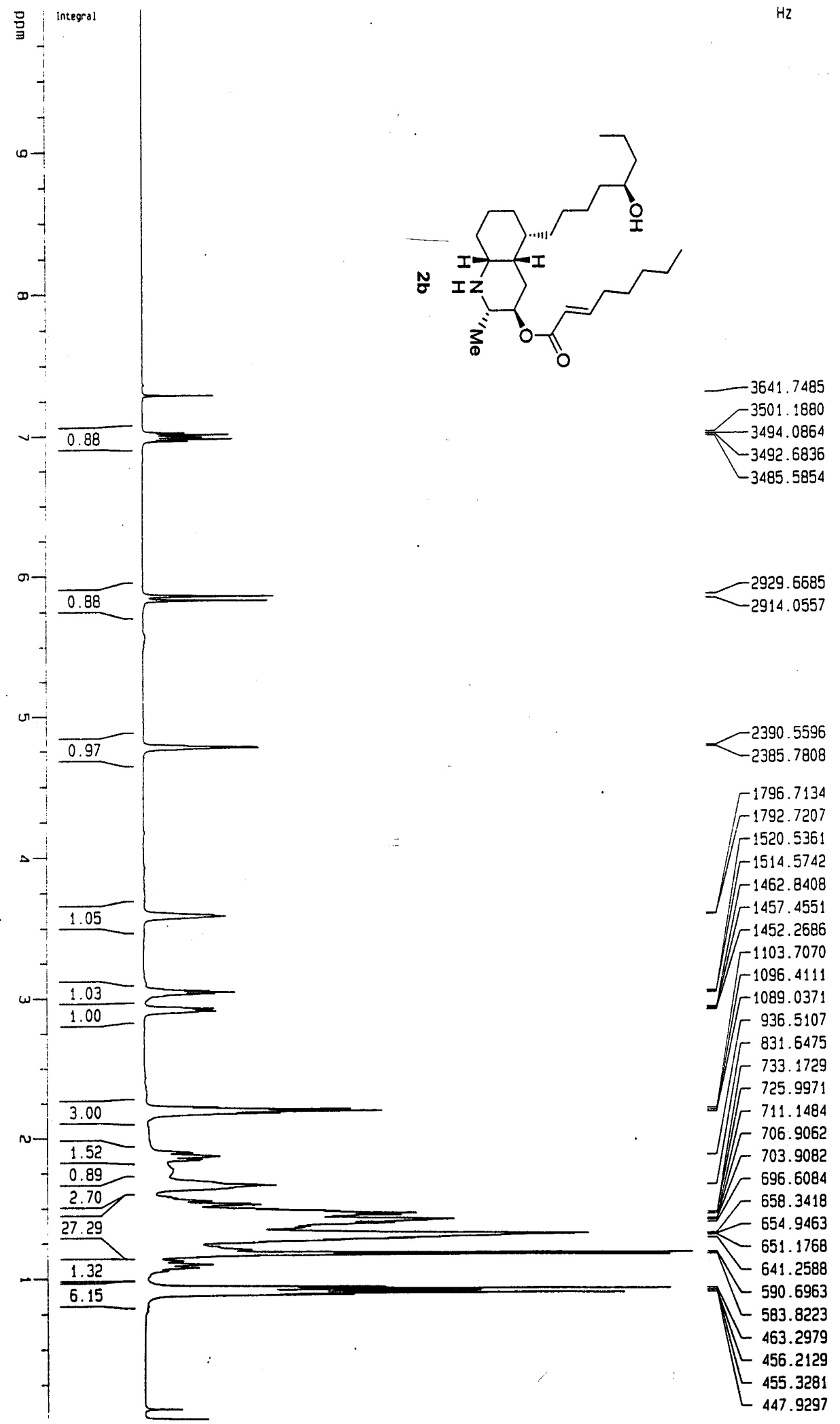



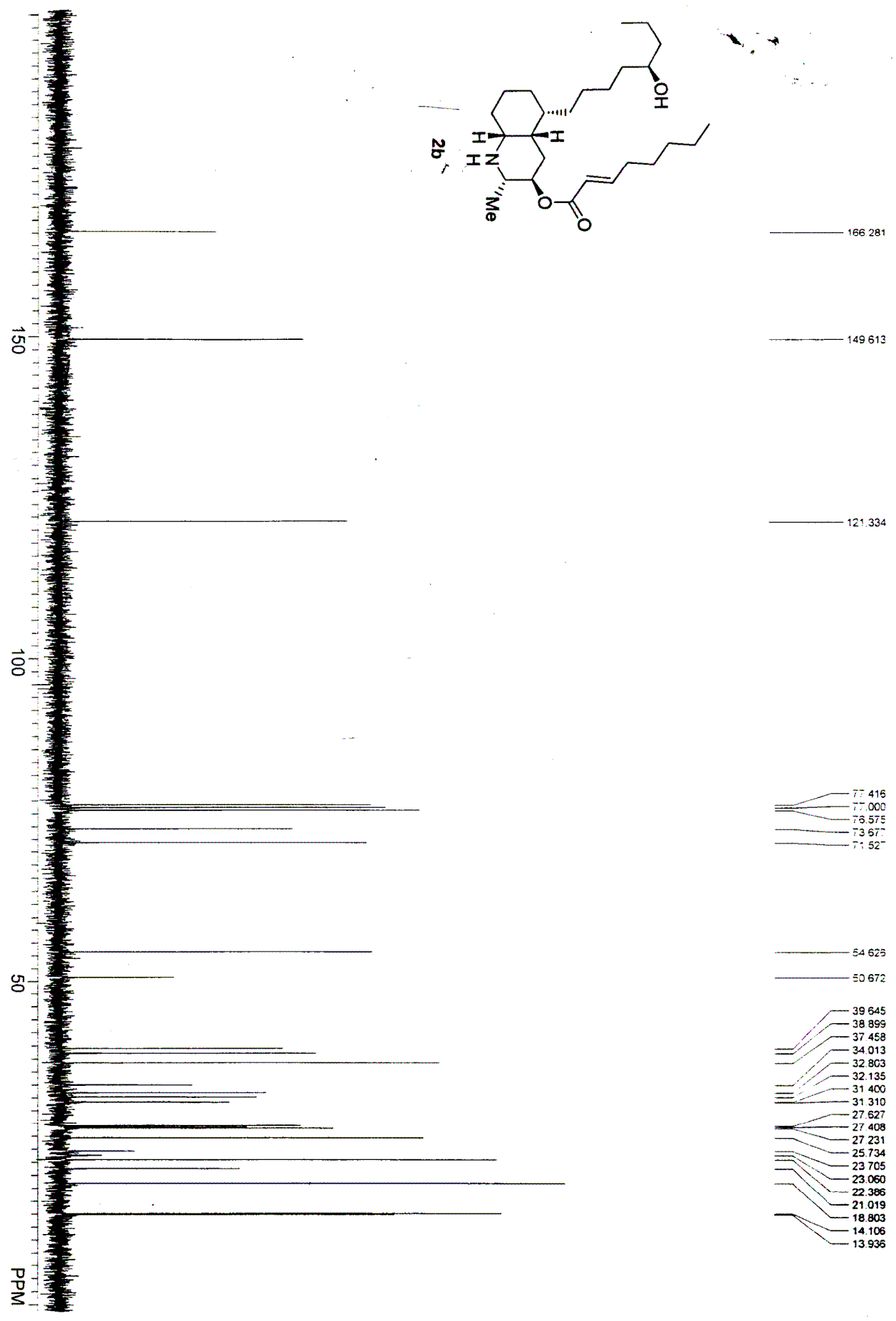

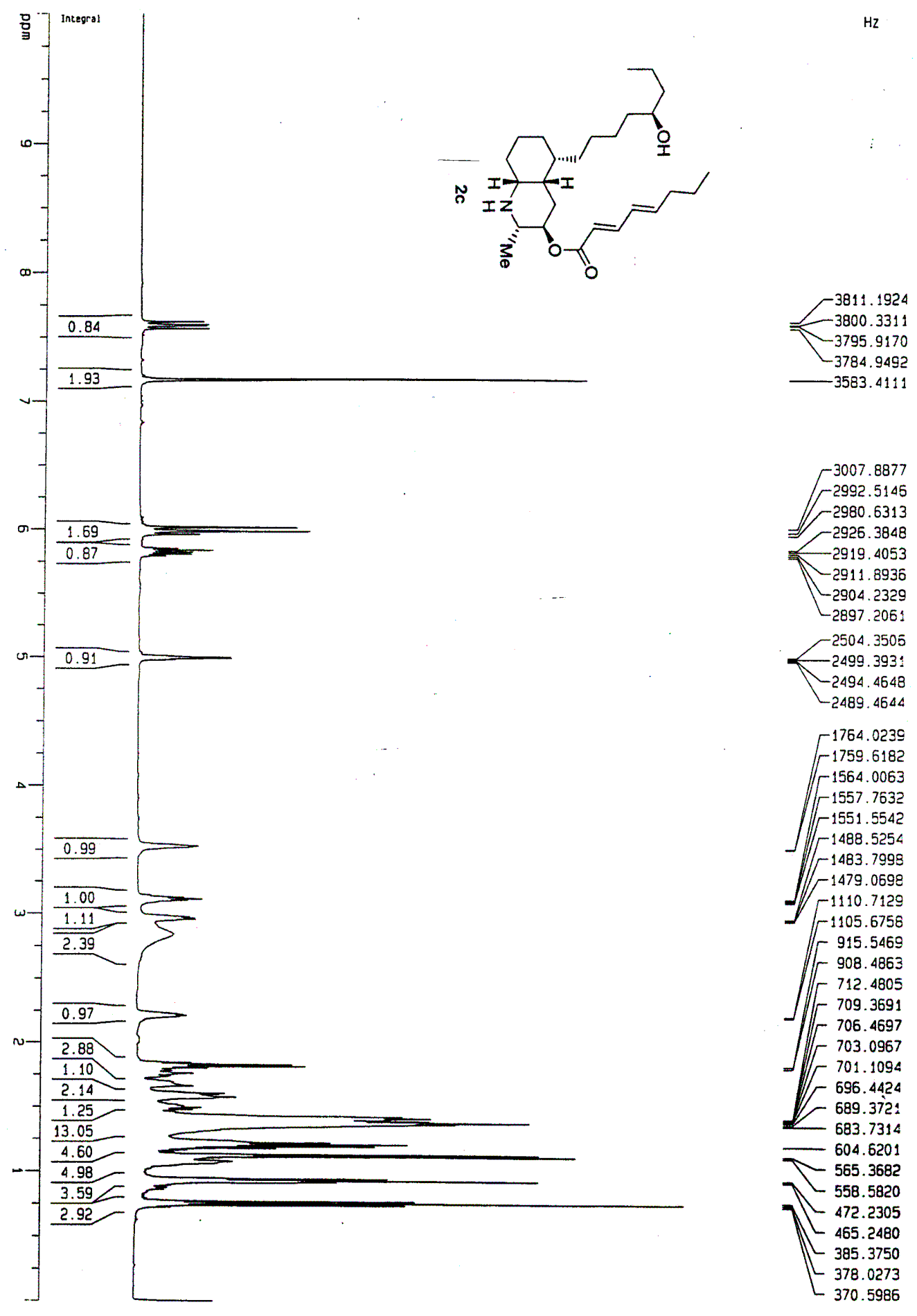

$-3007.8877$

2992.5145
-2980.6313

$-2980.6313$

D2926.3848

-2919.4053

$-2911.8936$

$-2904.2329$

$-2897.2061$

2504.3505

$-2499.3931$

$-2494.4648$

$-2489.4644$

1764.0239

$-1759.6182$ 1564.0063 $-1557.7632$ $-1551.5542$

-1488.5254 $r^{1483.7998}$ $-1479.0698$ d -1110.7129 - -1105.6758 $-915.5469$ f 908.4863 712.4805 ] -709.3691 ] 706.4697 F 703.0967 $=[701.1094$ - 696.4424 $-689.372:$ 683.7314 604.6201 $-565.3682$ 7558.5820 7 -472.2305

- 465.2480

- 385.3750

L 378.0273

L 370.5986

$\because \quad \quad \because$ 


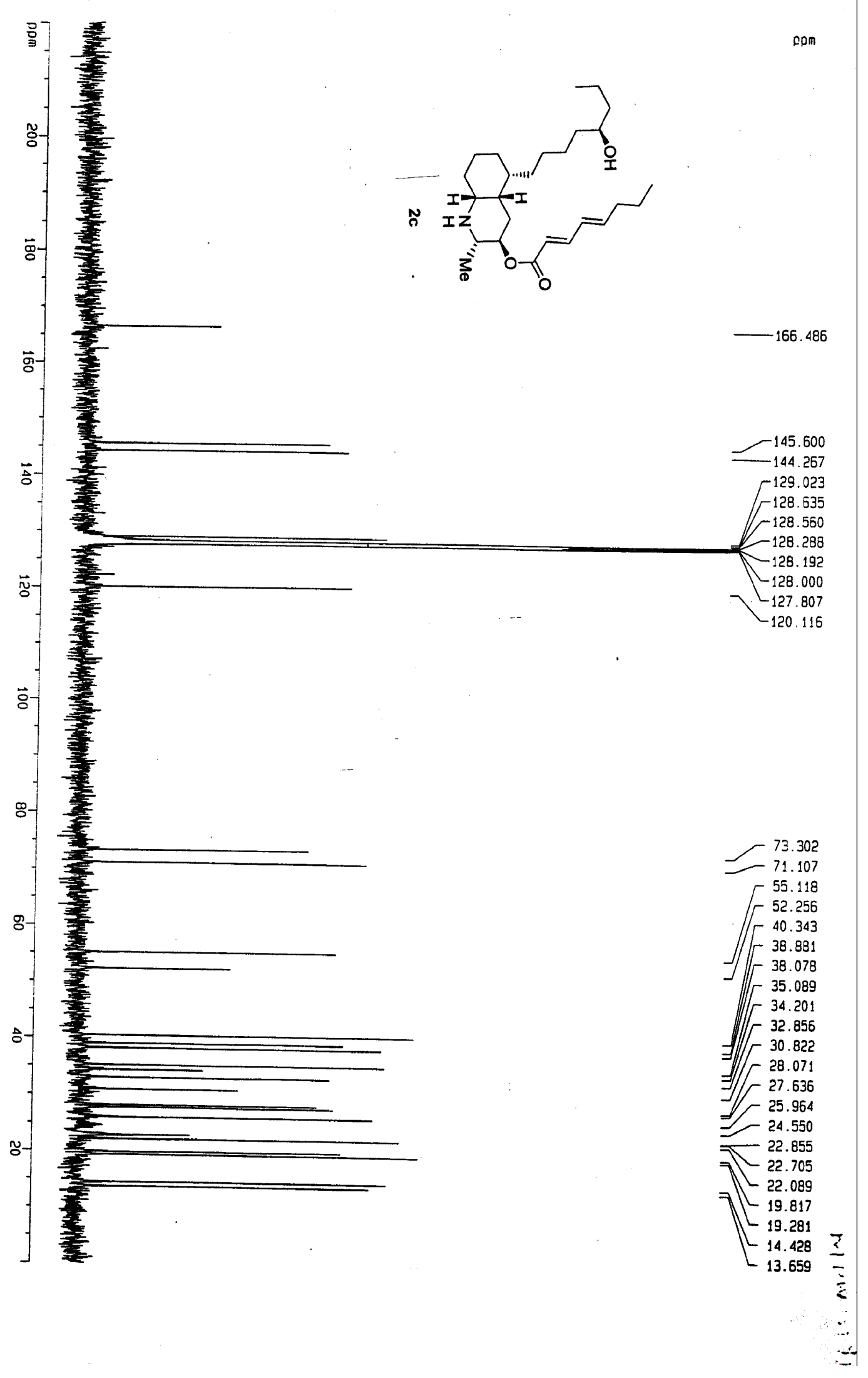

